\title{
Morphological characterisation and diagnostics of Xiphinema non-americanum group species (Nematoda: Longidoridae) from Romania using mutiplex PCR
}

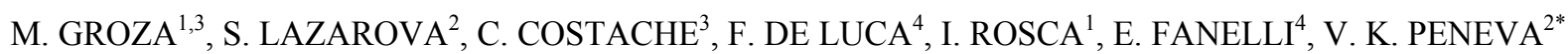 \\ ${ }^{1}$ University of Agronomic Sciences and Veterinary Medicine of Bucharest, 59 Blvd. Mărăşti, Bucharest, 011464, \\ România, E-mail: mariana_bonta@yahoo.com,ioanrosca_usamv@yahoo.com; ${ }^{2}$ Institute of Biodiversity and \\ Ecosystem Research, Bulgarian Academy of Sciences, 2 Gagarin Street, 1113 Sofia, Bulgaria, \\ E-mail: *vpeneva@ecolab.bas.bg, stela.lazarova@gmail.com; ${ }^{3}$ Central Phytosanitary Laboratory, 11 Voluntari Blv., \\ 077190 Voluntari, Ilfov, România, E-mail: claudia.costache@lccf.ro; ${ }^{4}$ Istituto per la Protezione delle Piante (IPP), \\ Sezione di Bari, Consiglio Nazionale delle Ricerche, (C.N.R.), Via G. Amendola 122/D, 70126 Bari, Italy, \\ E-mail:f.deluca@ba.ipp.cnr.it,e.fanelli@ba.ipp.cnr.it
}

\begin{abstract}
Summary
Additional data on the occurrence and distribution of Xiphinema non-americanum group species in Romania are provided. Xiphinema diversicaudatum, X. index, X. vuittenezi and $X$. italiae were recovered from vineyards and cherry fruit trees; adults and juvenile stages were described and analysed and the morphology/variability discussed. Multiplex PCR diagnostic test using species-specific primers designed by Wang et al. (2003) yielded amplification products with expected lengths for all screened populations of these four species. Two ribosomal markers (D2-D3 28 LSU rDNA and ITS) were sequenced and ITS RFLP patterns were obtained from two $X$. vuittenezi populations, which have shown some morphological differences. Comparatively low level of interpopulation genetic dissimilarity $(<1 \%)$ was revealed for both markers (for D2D3 - $0.5 \%$; for ITS $-0.7 \%$ ). Both populations of $X$. vuittenezi studied produced identical ITS-RFLP specific pattern that clearly identify this species.
\end{abstract}

Keywords: distribution; juvenile stages; D2-D3; ITS; RFLP

\section{Introduction}

Xiphinema index Thorne \& Allen 1950, X. diversicaudatum (Micoletzky, 1927), X. vuittenezi Luc, Lima, Weischer \& Flegg, 1964 and X. italiae Meyl, 1953 are ectoparasitic species known or suspected to be vectors of nepo-viruses: $X$. index transmits Grapevine Fanleaf Virus (virus that cause serious disease in viticulture regions) and $X$. diversicaudatum - Arabis Mosaic Virus and Strawberry Latent Ringspot Virus that have wide range of hosts among annual and perennial crops (MacFaralne et al., 2002). Xiphinema italiae, $X$. index and $X$. vuittenezi have been recorded from grapevine in different regions of Romania
(Romaşcu, 1971; Romaşcu \& Zinca, 1974); $X$. diversicaudatum was recorded also from the rhizosphere of strawberry, cherry, peach and plum trees (Romaşcu, 1981), however the data on their morphology and variability are limited and developmental stages were not described.

The purposes of this work are 1) to provide data on the morphology of adults and juvenile stages of these species from Romania; 2) to test the multiplex polymerase chain reaction using species-specific primers (Wang et al., 2003) and 3 ) to study the genetic variability of two $X$. vuittenezi populations which have shown differences in their morphology.

\section{Materials and methods}

Soil samples were collected from the rhizosphere of grapevine and cherry trees at a depth of $20-40 \mathrm{~cm}$, from different regions of the country. Nematodes were extracted from $200 \mathrm{~g}$ of soil by using the Baerman funnel method for 48 hours exposition, killed by gentle heat, and fixed in $4 \%$ formalin. The extracted specimens were processed in anhydrous glycerine by the Seinhorst method (1959) and mounted on permanent slides. Photographs were taken using an AxioImager.M2 - Carl Zeiss compound microscope equipped with digital camera (ProgRes C7) and specialised software (CapturePro Software 2.8). Measurements were made using an Olympus BX 41 light microscope with a drawing tube and digitizing tablet (CalComp Drawing Board III, GTCO CalCom Peripherals, Scottsdale, AZ, USA) and Digitrak 1.0f computer program (Philip Smith, John Hutton Institute Dundee, UK).

\section{Multiplex PCR}

DNA isolation was carried out following the procedure described by Wang et al. (2003) by placing 4 nematodes in 
$10 \mu \mathrm{l}$ of lysis buffer (1X Platinum Taq DNA polymerase/Invitrogen and $60 \mu \mathrm{g}$ of proteinase $\mathrm{K}$ per $\mathrm{ml}$ ) between two glass slides and crushed gently. The homogenate was taken up carefully with a pipette, transferred to $0.2 \mathrm{ml}$ Eppendorf tubes and frozen at $-80{ }^{\circ} \mathrm{C}$ for $15 \mathrm{~min}$. Subsequently, the tubes were incubated at $60{ }^{\circ} \mathrm{C}$ for $1 \mathrm{~h}$ and $95^{\circ} \mathrm{C}$ for $15 \mathrm{~min}$.

Amplification was carried out in a $25-\mu 1$ reaction mixture containing the $2.5 \mu \mathrm{l}$ lysis buffer (nematode lysate as PCR
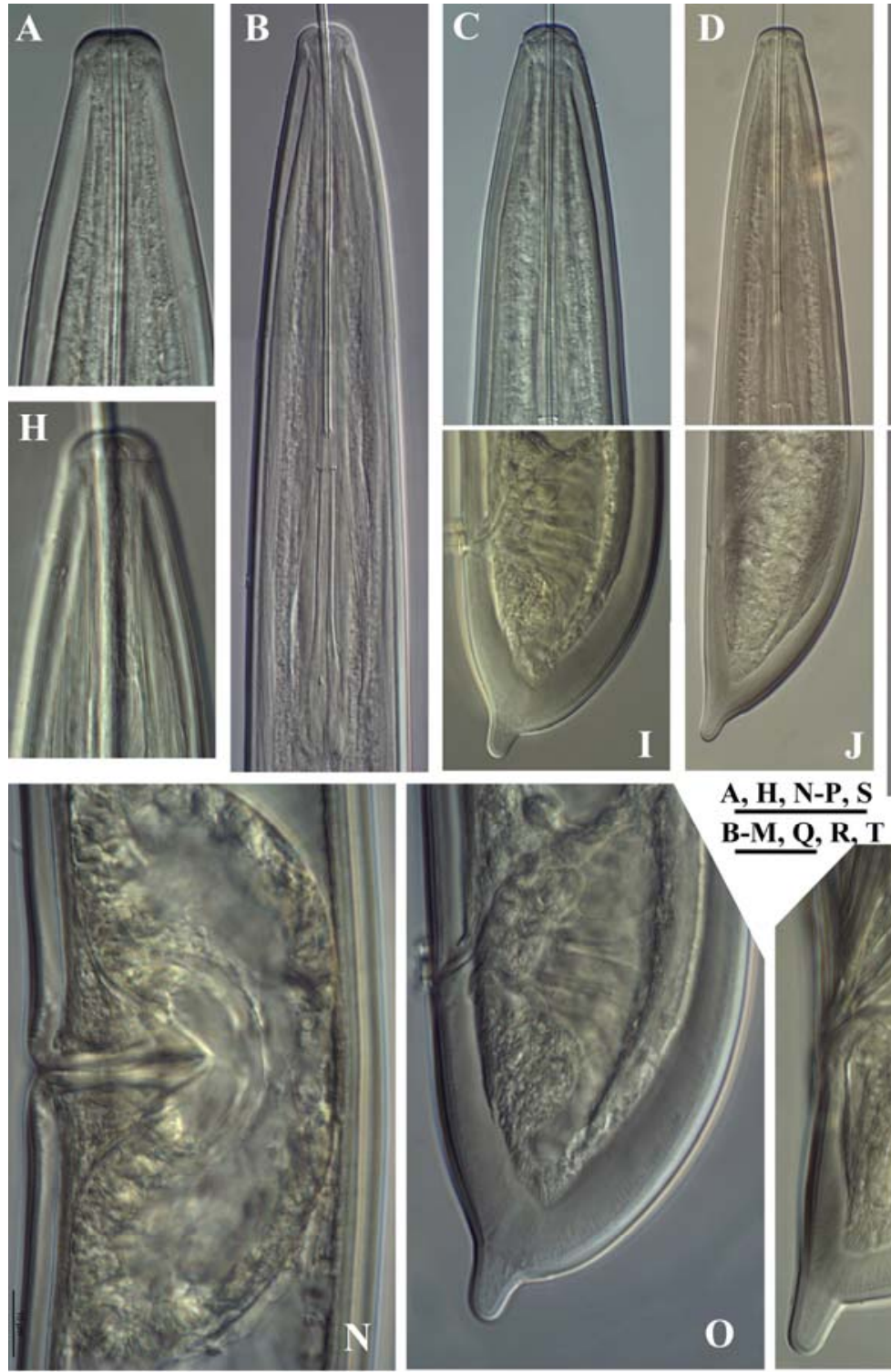

$\mathrm{J}$

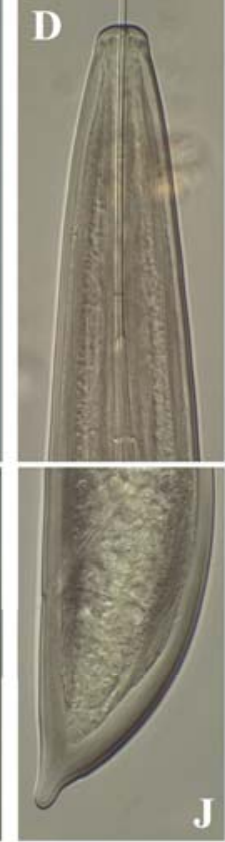

$A, \mathrm{H}, \mathrm{N}-\mathrm{P}, \mathrm{S}$
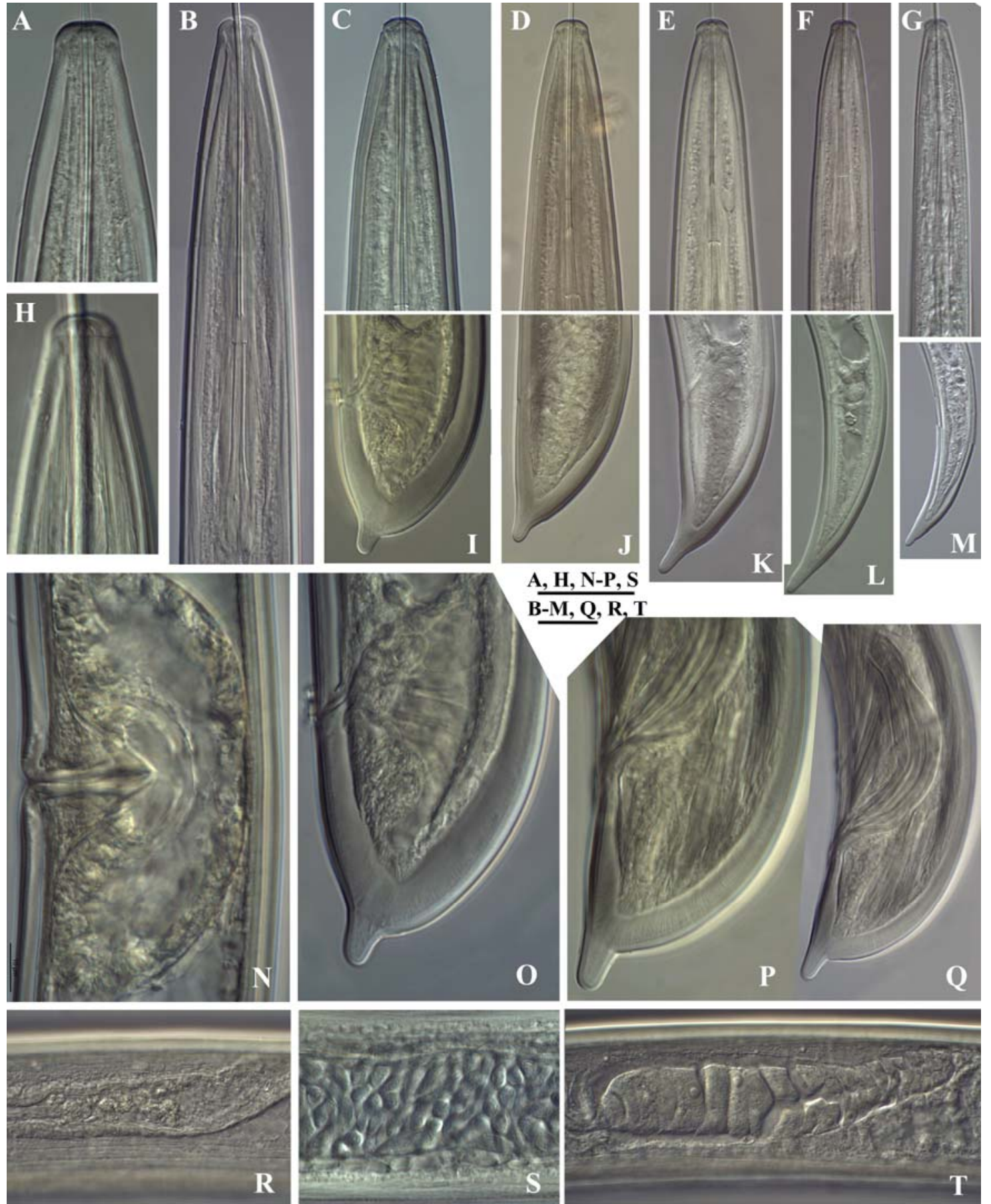

Fig. 1. Xiphinema diversicaudatum. Females, males and juveniles. A-G, Anterior ends of male (A, B), female (C) fourth to first juvenile stages (D - G); H, Amphid of male; I - M, Tails of female (I) and fourth- to first- juvenile stages (J-M); N, Vaginal region; O, Female tail; P, Male tail; Q, Male tail and spicules, R, Z-differentiation; S, Sperms in the testis; T, Ovary; Scale bars: $20 \mu \mathrm{m}$. 


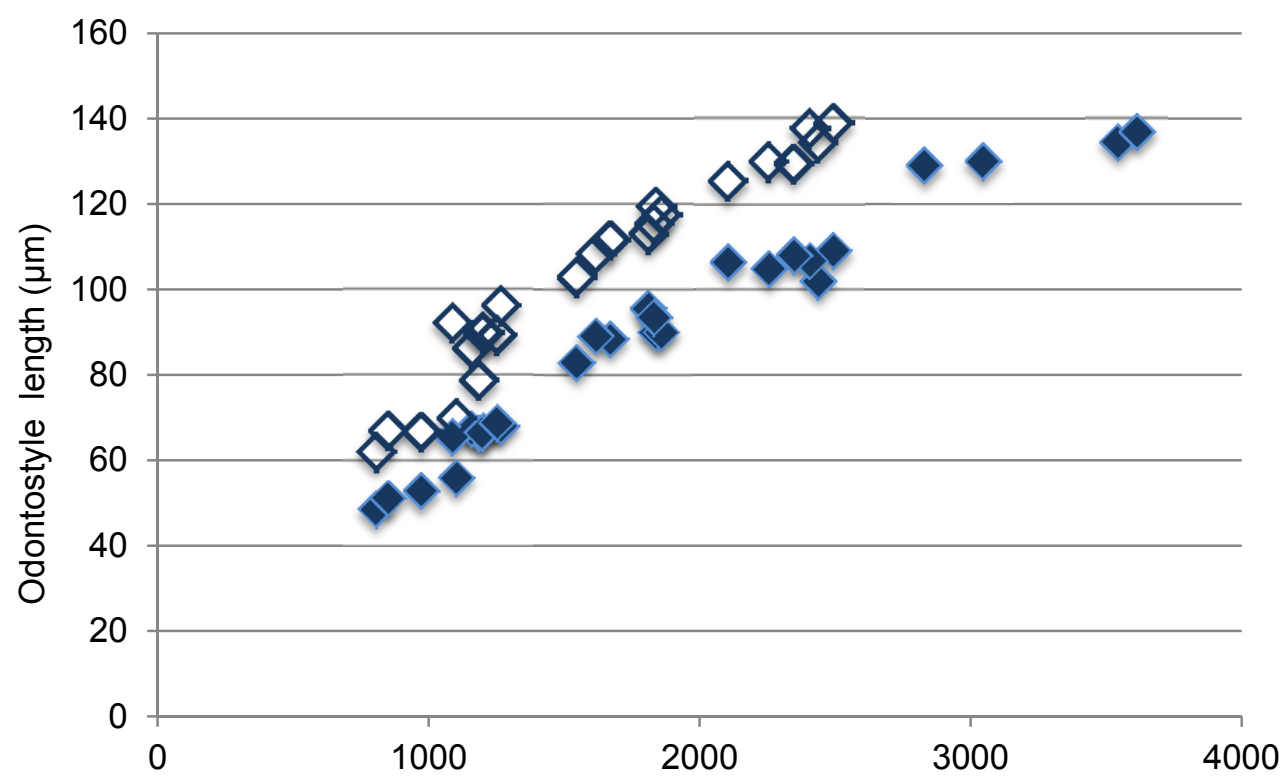

A

Body length $(\mu \mathrm{m})$

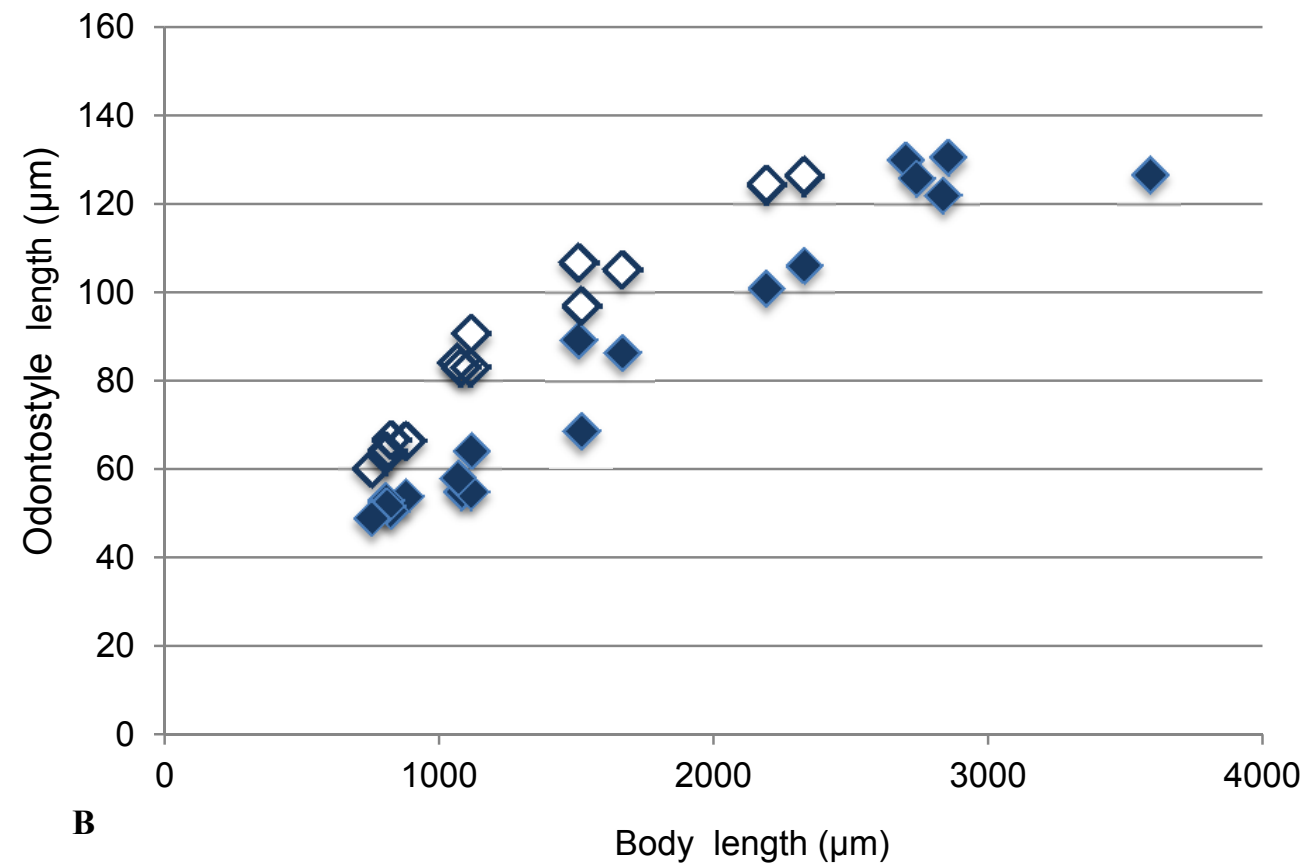

Fig. 2. Scatter plot of the functional

and replacement $(\diamond)$ odontostyle in relation to body length of the juvenile stages and adults $\mathrm{A}$, Xiphinema diversicaudatum $\mathrm{B}$, Xiphinema index

for $1 \mathrm{~min}$, and $72{ }^{\circ} \mathrm{C}$ for $1 \mathrm{~min} 30 \mathrm{~s}$, and ending with 1 cycle at $72{ }^{\circ} \mathrm{C}$ for $5 \mathrm{~min}$ and storage at $4{ }^{\circ} \mathrm{C}$.

Amplification products $(10 \mu \mathrm{l}$ PCR product) were separated on $1.5 \%$ agarose gel (Sigma) in $0.5 \mathrm{X}$ TBE at $100 \mathrm{~V}$ for 40 minutes and visualized with GENi photo documentation system (Syngene).

DNA extraction, PCR amplification, sequencing and RFLP analysis

The following analyses were performed for both $X$. vuittenezi populations, which have shown differences in mor- phometrics. Two ribosomal genes (D2-D3 28LSU rDNA and ITS) were sequenced and ITS RFLP pattern was obtained. Genomic DNA was extracted from 10 individual nematodes as described by De Luca et al. (2004). The crude DNA isolated from each individual nematode was directly amplified by using two sets of universal primers. The ITS containing region was amplified using the forward primer 18S (5-TGATTACGTCCCTGCCTTT-3) and the reverse primer 26S (5-TTTCACTCGCCGTTACTAAGG3) (Vrain et al., 1992), while the D2-D3 region using the forward primer D2A (5-ACAAGTACCGTGAGGGAAAG 
Table 1. Measurements of females, males and juvenile stages of Xiphinema diversicaudatum from Voineşti (mean \pm standard deviation, with range). All measurements in micrometers except $\mathrm{L}$ in $\mathrm{mm}$.

\begin{tabular}{|c|c|c|c|c|c|c|}
\hline Character & Females & Males & J1 & $\mathbf{J} 2$ & $\mathbf{J 3}$ & J4 \\
\hline $\mathrm{n}$ & $\mathrm{n}=2$ & $\mathrm{n}=2$ & $\mathrm{n}=4$ & $\mathrm{n}=7$ & $\mathrm{n}=7$ & $\mathrm{n}=6$ \\
\hline \multirow{2}{*}{$\mathrm{L}$} & $3.54,2.83$ & $3.61,3.04$ & $0.93 \pm 0.13$ & $1.19 \pm 0.595$ & $1.74 \pm 0.125$ & $2.34 \pm 0.14$ \\
\hline & & & $0.816-1.10$ & $1.08-1.26$ & $1.54-1.86$ & $2.10-2.49$ \\
\hline \multirow[t]{2}{*}{$\mathrm{a}$} & $59.7,52.2$ & $70.5,64.1$ & $41.9 \pm 3.3$ & $42.8 \pm 1.9$ & $47.7 \pm 2.6$ & $51.0 \pm 7.9$ \\
\hline & & & $38.7-45.9$ & $40.4-45.1$ & $43.9-51.0$ & $43-61$ \\
\hline $\mathrm{b}$ & 7.7 & $7.6,6.6$ & $\begin{array}{l}3.9 \pm 0.5 \\
3.4-4.5\end{array}$ & $\begin{array}{l}4.1 \pm 0.3 \\
3.7-4.5\end{array}$ & $\begin{array}{l}4.7 \pm 0.2 \\
4.4-4.9\end{array}$ & $\begin{array}{l}5.5 \pm 0.2 \\
5.2-5.9\end{array}$ \\
\hline \multirow[t]{2}{*}{ c } & $65.8,65.2$ & $58.4,60.0$ & $16.0 \pm 1.8$ & $18.4 \pm 1.7$ & $28.8 \pm 3.5$ & $49.9 \pm 9.8$ \\
\hline & $05.8,05.2$ & $58.4,00.0$ & $14.1-17.8$ & $16.6-21.1$ & $23.5-33.7$ & $40.7-65.4$ \\
\hline$c^{\prime}$ & $1.1,1.0$ & $1.4,1.1$ & $\begin{array}{l}4.0 \pm 0.3 \\
3.8-4.4\end{array}$ & $\begin{array}{l}3.1 \pm 0.3 \\
26-3.4\end{array}$ & $2.1 \pm 0.3$ & $1.3 \pm 0.3$ \\
\hline $\begin{array}{l}\text { V (\%)/ } \\
\text { Spicules length }\end{array}$ & $41.7,44.4$ & 74,75 & & & & \\
\hline G1 (\%) & $18.9,22.4$ & & & & & \\
\hline G2 (\%) & $22.0,22.4$ & & & & & \\
\hline g & 7779 & 9082 & $5.4 \pm 0.5$ & $6.2 \pm 0.4$ & $7.6 \pm 0.5$ & $8.3 \pm 0.6$ \\
\hline & $1.1,1.9$ & $9.0,8.2$ & $4.8-6.1$ & $5.6-6.6$ & $7.0-8.6$ & $7.3-9.2$ \\
\hline $\mathrm{d}^{\prime}$ & 3.0 .3 .1 & 29.27 & $2.2 \pm 0.1$ & $2.5 \pm 0.2$ & $2.7 \pm 0.1$ & $3.0 \pm 0.2$ \\
\hline $\mathrm{d}$ & $3.0,3.1$ & $2.9,2.1$ & $2.0-2.4$ & $2.2-2.8$ & $2.6-3.0$ & $2.8-3.3$ \\
\hline Anterior end to guide ring & 103,97 & 113,109 & $\begin{array}{l}40.9 \pm 3.4 \\
37-45\end{array}$ & $\begin{array}{l}53.3 \pm 2.3 \\
50-57\end{array}$ & $\begin{array}{c}74.1 \pm 5.1 \\
69-84\end{array}$ & $\begin{array}{l}91.2 \pm 4.9 \\
84-96\end{array}$ \\
\hline Odontostyle & 135,129 & 137,130 & $\begin{array}{l}52.3 \pm 3.1 \\
49-56\end{array}$ & $\begin{array}{c}67.2 \pm 1.1 \\
66-69\end{array}$ & $\begin{array}{l}90.1 \pm 4.0 \\
83-96\end{array}$ & $\begin{array}{c}106.2 \pm 2.5 \\
102-109\end{array}$ \\
\hline & & & $66.6 \pm 3.2$ & $89.1 \pm 5.4$ & $112.8 \pm 5.6$ & $132.9 \pm 5.2$ \\
\hline Replacement odontostyle & & & $62-70$ & $79-96$ & $103-120$ & $126-139$ \\
\hline Odontophore & 89,78 & $82.5,81$ & $\begin{array}{c}35.9 \pm 1.0 \\
34-37\end{array}$ & $\begin{array}{c}50.1 \pm 3.6 \\
43-53\end{array}$ & $\begin{array}{l}60.2 \pm 3.4 \\
55-64\end{array}$ & $\begin{array}{c}70.0 \pm 3.8 \\
66-76\end{array}$ \\
\hline Pharynx length & $460 \ldots$ & 475,464 & $241.5 \pm 2.5$ & $292.6 \pm 16.8$ & $369.1 \pm 19.5$ & $425.3 \pm 21.0$ \\
\hline & $400,-$ & $4 / 5,404$ & $238-244$ & $263-307$ & $337-391$ & $400-447.5$ \\
\hline Tail & 54,43 & 62,51 & $\begin{array}{l}58.2 \pm 3.6 \\
54-62\end{array}$ & $\begin{array}{c}65.0 \pm 4.7 \\
60-71\end{array}$ & $\begin{array}{c}60.6 \pm 5.1 \\
55-71\end{array}$ & $\begin{array}{l}48.0 \pm 7.1 \\
37-55\end{array}$ \\
\hline Hyaline part of tail & 19,19 & 23,17 & $10.5 \pm 1.2$ & $15.7 \pm 2.1$ & $19.3 \pm 1.7$ & $17.7 \pm 1.8$ \\
\hline & 19,19 & $23,1 /$ & $9-12$ & $12.5-19$ & $17-22.5$ & $16-20$ \\
\hline $\begin{array}{l}\text { Body diameter at: } \\
\text { - lip region }\end{array}$ & 13,12 & $12.5,13$ & $\begin{array}{c}7.6 \pm 0.2 \\
7-8\end{array}$ & $\begin{array}{c}8.6 \pm 0.4 \\
8-9\end{array}$ & $\begin{array}{c}9.7 \pm 0.5 \\
9-10\end{array}$ & $\begin{array}{l}11.0 \pm 0.6 \\
10-12\end{array}$ \\
\hline - guide ring & 41,38 & 37,36 & $\begin{array}{c}16.3 \pm 0.8 \\
15-17\end{array}$ & $\begin{array}{c}21.3 \pm 1.0 \\
19-22\end{array}$ & $\begin{array}{l}26.4 \pm 0.8 \\
25-27.5\end{array}$ & $\begin{array}{l}33.2 \pm 2.1 \\
30-36\end{array}$ \\
\hline - base of pharynx & 50,49 & 46,45 & $\begin{array}{l}21.6 \pm 0.7 \\
21-23\end{array}$ & $\begin{array}{c}26.6 \pm 1.2 \\
25-28\end{array}$ & $\begin{array}{c}35.0 \pm 3.0 \\
30-39\end{array}$ & $\begin{array}{c}44.4 \pm 5.3 \\
38-50\end{array}$ \\
\hline - mid-body/at vulva & 59,54 & $51,47.5$ & $\begin{array}{c}22.2 \pm 1.4 \\
21-24\end{array}$ & $\begin{array}{c}27.8 \pm 1.5 \\
26-30\end{array}$ & $\begin{array}{c}36.5 \pm 3.7 \\
30-42\end{array}$ & $\begin{array}{c}46.6 \pm 6.2 \\
38-54\end{array}$ \\
\hline - anus & 48,44 & $43,44.5$ & $\begin{array}{c}14.6 \pm 1.2 \\
14-16\end{array}$ & $\begin{array}{c}21.0 \pm 1.4 \\
19-23\end{array}$ & $\begin{array}{l}29.0 \pm 2.2 \\
25-32\end{array}$ & $\begin{array}{c}38.5 \pm 4.1 \\
33-44\end{array}$ \\
\hline - hyaline part & 27,33 & 26,19 & $\begin{array}{l}5.8 \pm 0.8 \\
5-7\end{array}$ & $\begin{array}{c}7.8 \pm 0.8 \\
6.5-9\end{array}$ & $\begin{array}{c}11.1 \pm 1.1 \\
9-12\end{array}$ & $\begin{array}{c}18.3 \pm 2.3 \\
16-21\end{array}$ \\
\hline
\end{tabular}

TTG-3) and the reverse primer D3B (5-TCGGAAGGAAC CAGCTACTA-3) (Castillo et al., 2003). PCR cycling conditions used for amplification of both segments were identical: an initial denaturation at $94{ }^{\circ} \mathrm{C}$ for $5 \mathrm{~min}$, followed by 35 cycles of denaturation at $94{ }^{\circ} \mathrm{C}$ for $50 \mathrm{~s}$, annealing at $55{ }^{\circ} \mathrm{C}$ for $50 \mathrm{~s}$ and extension at $72{ }^{\circ} \mathrm{C}$ for 1 min and a final step at $72{ }^{\circ} \mathrm{C}$ for $7 \mathrm{~min}$. The size of amplification products was determined by comparison with the molecular weight marker ladder 100 (Fermentas, St Leon-Rot, Germany) following electrophoresis of $10 \mu \mathrm{l}$ on a $1 \%$ agarose gel.
Sequencing: PCR products of the D2-D3 and ITS containing region from three individual nematodes for each population were purified for sequencing using the protocol listed by manufacturer (High Pure PCR elution kit, Roche, Germany). Purified DNA fragments were cloned and sequenced in both directions. The sequences have been submitted to GenBank with the following accession numbers HG329722 - HG329724. A BLAST (Basic Local Alignment Search Tool) search at NCBI (National Center for Biotechnology Information) was performed using $X$. vuittenezi D2-D3 and ITS sequences as queries to confirm 

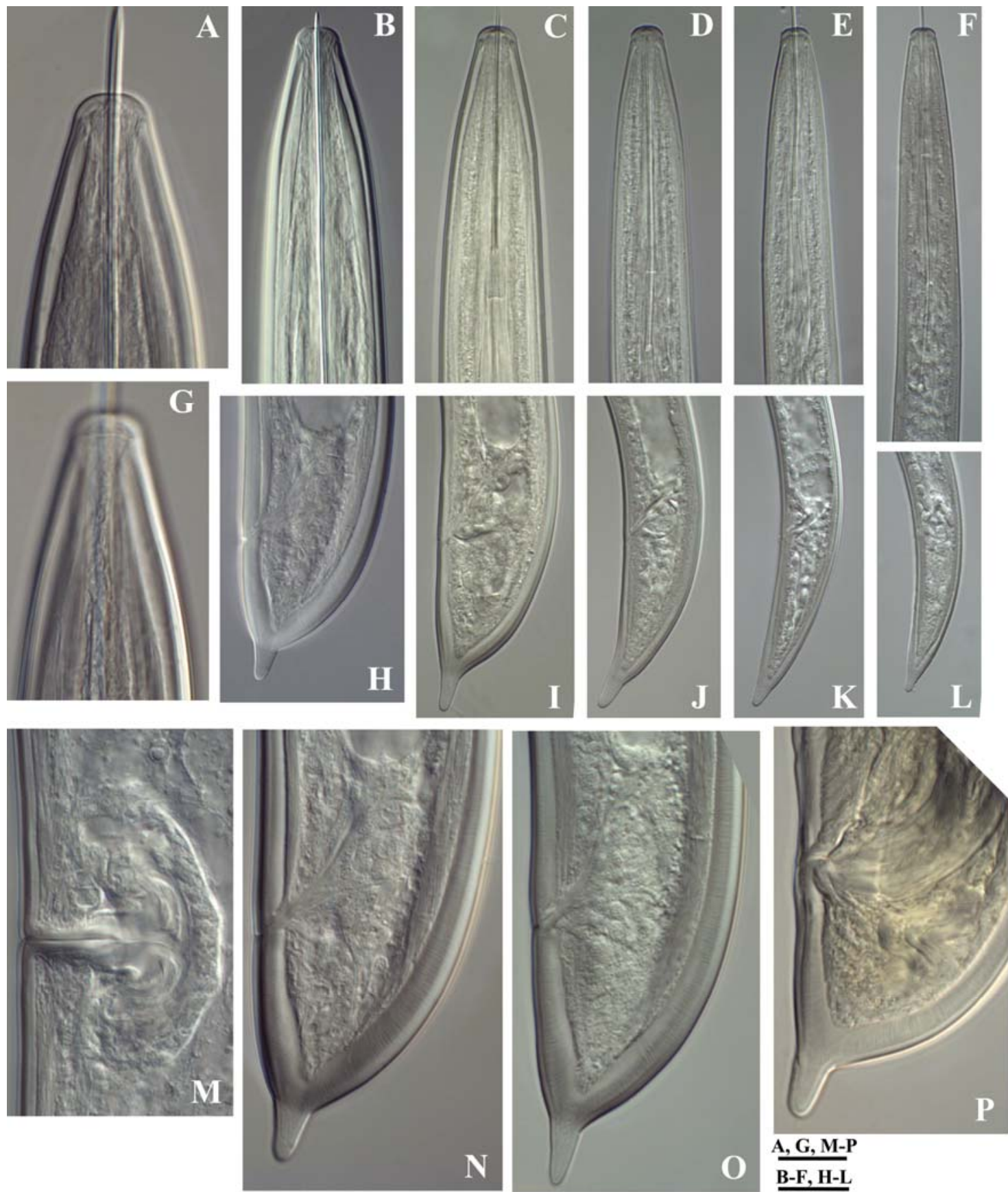

Fig. 3. Xiphinema index. Females, male and juveniles. A- G, Anterior ends of female (A, B), fourth to first juvenile stages (C-F); G, Amphid of female; $\mathrm{H}-\mathrm{L}$, Tails of female $(\mathrm{H})$ and fourth- to first- juvenile stages $(\mathrm{I}-\mathrm{L}) ; \mathrm{M}$, Vaginal region; N, O, Female tail variation; $\mathrm{P}$, Male tail;

$$
\text { Scale bars: A, G, M-P: } 12 \mu \mathrm{m} \text {; B - F, H - L: } 20 \mu \mathrm{m}
$$

their nematode origins (Altschul et al., 1997).

The acquired sequences and those available at NCBI were aligned using ClustalX 2.1 programme (Jeanmougin et al. 1998). Subsequently both ends were trimmed and edited in order to remove the amplification mistakes and sequence divergences were calculated using MEGA 5.0 (Tamura et al. 2011). RFLP analysis: Ten $\mu$ l of each PCR product from two individual nematodes of both populations was digested with five units of the following restriction enzymes: BamHI, DdeI, RsaI, AluI, HinfI and XbaI (Roche Diagnostics, Manheim, Germany). Digested products were separated onto a
$2.5 \%$ agarose gel by electrophoresis, stained with ethidium bromide, visualised on a UV transilluminator and recorded by photography with a digital system.

\section{Results and discussion}

\section{Taxonomy}

Xiphinema diversicaudatum (Micoletzky, 1927) Thorne, 1939 (Figs. 1 and 2A)

Measurements

See Table 1. 
Description

Females: Body assuming an open $\mathrm{C}$-shape when heat relaxed; head region rounded, almost continuous with the rest of the body; amphidial aperture large, occupying c. 80 - $90 \%$ of the corresponding labial diameter; cuticle at postlabial region $3-4 \mu \mathrm{m}$, at mid-body $4 \mu \mathrm{m}$, on tail $7 \mu \mathrm{m}$. Pharyngeal bulb measuring 78, $89 \times 25,26 \mu \mathrm{m}$. Uterus tripartite, $\mathrm{Z}$ differentiation in the form of irregular flowerlike bodies and uterine spines. Rectum 30, $27 \mu \mathrm{m}$ long; prerectum 469, $481 \mu \mathrm{m}$; tail convex conoid, dorsally rounded with a ventral peg $7-8.5 \mu \mathrm{m}$ long, 5 caudal pores. Blind canal present.

Males: Common, morphologically similar to females, body more coiled in the posterior region; cuticle at postlabial region $3 \mu \mathrm{m}$, at mid body $5-6.5 \mu \mathrm{m}$, pharyngeal bulb measuring 81.5, $107 \times 25,21 \mu \mathrm{m}$; spicules massive 74,75 $\mu \mathrm{m}$ long; ventromedian supplements $1+3$ and $1+4$, irregularly spaced; peg $11 \mu \mathrm{m}$ long.

Table 2. Measurements of females and juvenile stages of Xiphinema index from Valea Călugărească (mean \pm standard deviation, with range). All measurements in micrometers except $\mathrm{L}$ in $\mathrm{mm}$.

\begin{tabular}{|c|c|c|c|c|c|c|}
\hline Character & Females & Males & J1 & $\mathbf{J 2}$ & $\mathbf{J 3}$ & J4 \\
\hline $\mathrm{n}$ & $\mathrm{n}=4$ & $\mathrm{n}=1$ & $\mathrm{n}=5$ & $\mathrm{n}=4$ & $\mathrm{n}=3$ & $\mathrm{n}=3$ \\
\hline $\mathrm{L}$ & $\begin{array}{c}2.80 \pm 0.10 \\
2.70-2.925\end{array}$ & 3.59 & $\begin{array}{l}0.81 \pm 0.44 \\
0.75-0.88\end{array}$ & $\begin{array}{l}1.09 \pm 0.24 \\
1.06-1.11\end{array}$ & $1.66,1.52,1.51$ & $2.33,2.19,2.40$ \\
\hline $\mathrm{a}$ & $\begin{array}{l}55.0 \pm 3.0 \\
51.9-58.5\end{array}$ & 63.4 & $\begin{array}{c}42.9 \pm 1.6 \\
40.7-44.9\end{array}$ & $\begin{array}{c}43.8 \pm 1.7 \\
41.8-45.7\end{array}$ & $50.5,47.5,54.3$ & $54.1,56.3,56.9$ \\
\hline $\mathrm{b}$ & $\begin{array}{l}7.1 \pm 1.0 \\
6.1-8.3\end{array}$ & & $\begin{array}{l}3.7 \pm 0.3 \\
3.5-4.1\end{array}$ & $\begin{array}{l}4.2 \pm 0.2 \\
4.0-4.5\end{array}$ & $4.9,4.8,4.0$ & $6.2,5.7,5.2$ \\
\hline $\mathrm{c}$ & $\begin{array}{r}70.9 \pm 11.0 \\
59.0-83.4\end{array}$ & 81.0 & $\begin{array}{c}19.2 \pm 1.3 \\
17.7-21.0\end{array}$ & $\begin{array}{c}22.6 \pm 1.3 \\
21.5-24.2\end{array}$ & $31.2,29.9,31.3$ & $52.3,46.0,43.8$ \\
\hline$c^{\prime}$ & $\begin{array}{l}1.2 \pm 0.2 \\
0.9-1.4\end{array}$ & 1.0 & $\begin{array}{l}3.2 \pm 0.2 \\
2.9-3.5\end{array}$ & $\begin{array}{l}2.7 \pm 0.2 \\
2.6-3.0\end{array}$ & $2.2,2.2,2.3$ & $1.5,1.5,1.6$ \\
\hline V (\%)/Spicules length & $\begin{array}{c}42.9 \pm 1.6 \\
41.0-45.0\end{array}$ & 69 & & & & \\
\hline G1 (\%) & $\begin{array}{c}13.3 \pm 1.7 \\
12.3-15.8\end{array}$ & & & & & \\
\hline G2 (\%) & $\begin{array}{l}10.7 \pm 2.9 \\
7.4-14.5\end{array}$ & & & & & \\
\hline d & $\begin{array}{l}9.4 \pm 0.2 \\
9.1-9.6\end{array}$ & 11.1 & $\begin{array}{l}6.0 \pm 0.4 \\
5.6-6.5\end{array}$ & $\begin{array}{l}6.4 \pm 0.8 \\
5.5-7.5\end{array}$ & $7.8,5.8,8.6$ & $9.9,7.8,8.7$ \\
\hline $\mathrm{d}^{\prime}$ & $\begin{array}{l}3.0 \pm 0.1 \\
2.9-3.1\end{array}$ & 4.3 & $\begin{array}{l}2.3 \pm 0.1 \\
2.2-2.4\end{array}$ & $\begin{array}{l}2.6 \pm 0.1 \\
2.4-2.7\end{array}$ & $2.8,2.7,2.9$ & $3.1,3.1,3.2$ \\
\hline Anterior end to guide ring & $\begin{array}{c}109.2 \pm 2.9 \\
106-112\end{array}$ & 121 & $\begin{array}{c}39.2 \pm 1.9 \\
37-41\end{array}$ & $\begin{array}{c}47.8 \pm 8.5 \\
41-60\end{array}$ & $72,52,68$ & $97,76,85$ \\
\hline Odontostyle & $\begin{array}{c}127.3 \pm 4.0 \\
122-131\end{array}$ & 127 & $\begin{array}{c}51.7 \pm 1.9 \\
49-54\end{array}$ & $\begin{array}{c}57.3 \pm 5.1 \\
52-64\end{array}$ & $87,69,89$ & $106,101,104$ \\
\hline Replacement odontostyle & & & $\begin{array}{c}64.1 \pm 2.6 \\
60-67\end{array}$ & $\begin{array}{c}85.3 \pm 3.7 \\
83-91\end{array}$ & $105,97,107$ & $126,124.5$ \\
\hline Odontophore & $\begin{array}{c}73.8 \pm 2.1 \\
72-76\end{array}$ & 76 & $\begin{array}{c}33.0 \pm 2.1 \\
30-35\end{array}$ & $\begin{array}{c}44.8 \pm 1.8 \\
43-47\end{array}$ & $56,52,51.5$ & $69,67,63$ \\
\hline Pharynx length & $\begin{array}{l}395.1 \pm 47.5 \\
343-447.5\end{array}$ & & $\begin{array}{c}219.4 \pm 20.0 \\
185-234\end{array}$ & $\begin{array}{c}263.0 \pm 11.6 \\
250-277\end{array}$ & $341,319,376$ & $375,386,460$ \\
\hline Tail & $\begin{array}{c}39.8 \pm 5.4 \\
34-46\end{array}$ & 44 & $\begin{array}{c}42.5 \pm 2.0 \\
41-45\end{array}$ & $\begin{array}{c}48.4 \pm 1.8 \\
46-50\end{array}$ & $53,51,48$ & $44.5,48,55$ \\
\hline Hyaline part of tail & $\begin{array}{c}15.5 \pm 1.6 \\
14-18\end{array}$ & 17 & $\begin{array}{c}7.6 \pm 0.3 \\
7-8\end{array}$ & $\begin{array}{c}9.1 \pm 1.0 \\
8-10\end{array}$ & $11,11,11.5$ & $16,15,17$ \\
\hline $\begin{array}{l}\text { Body diameter at: } \\
\text { - lip region }\end{array}$ & $\begin{array}{c}11.7 \pm 0.5 \\
11-12\end{array}$ & 11 & $\begin{array}{c}6.5 \pm 0.2 \\
6-7\end{array}$ & $\begin{array}{l}7.5 \pm 0.4 \\
7-8\end{array}$ & $9,9,8$ & $10,10,10$ \\
\hline - guide ring & $\begin{array}{c}35.1 \pm 1.5 \\
34-37\end{array}$ & 47 & $\begin{array}{l}15.1 \pm 0.3 \\
15-15.5\end{array}$ & $\begin{array}{c}19.0 \pm 1.4 \\
18-21\end{array}$ & $26,24,23$ & $30,30,31$ \\
\hline - base of pharynx & $\begin{array}{c}44.0 \pm 1.8 \\
42-46\end{array}$ & & $\begin{array}{c}18.8 \pm 0.7 \\
18-20\end{array}$ & $\begin{array}{l}23.5 \pm 1.2 \\
22-25\end{array}$ & $32,30,27$ & $39,38,41$ \\
\hline - mid-body/at vulva & $\begin{array}{l}50.6 \pm 2.8 \\
48.5-55\end{array}$ & 57 & $\begin{array}{c}18.9 \pm 0.8 \\
18-20\end{array}$ & $\begin{array}{c}25.0 \pm 1.2 \\
23-26\end{array}$ & $33,32,28$ & $43,39,42$ \\
\hline - anus & $\begin{array}{c}34.1 \pm 1.8 \\
32-36\end{array}$ & 43 & $\begin{array}{c}13.3 \pm 0.6 \\
13-14\end{array}$ & $\begin{array}{c}17.9 \pm 1.1 \\
16-19\end{array}$ & $24,23,21$ & $30,31,34$ \\
\hline - hyaline part & $\begin{array}{c}16.9 \pm 2.0 \\
15-20\end{array}$ & 20.5 & $\begin{array}{l}5.5 \pm 0.4 \\
5-6\end{array}$ & $\begin{array}{c}6.2 \pm 0.8 \\
6-7\end{array}$ & $7,9,6$ & $13,12,13$ \\
\hline
\end{tabular}



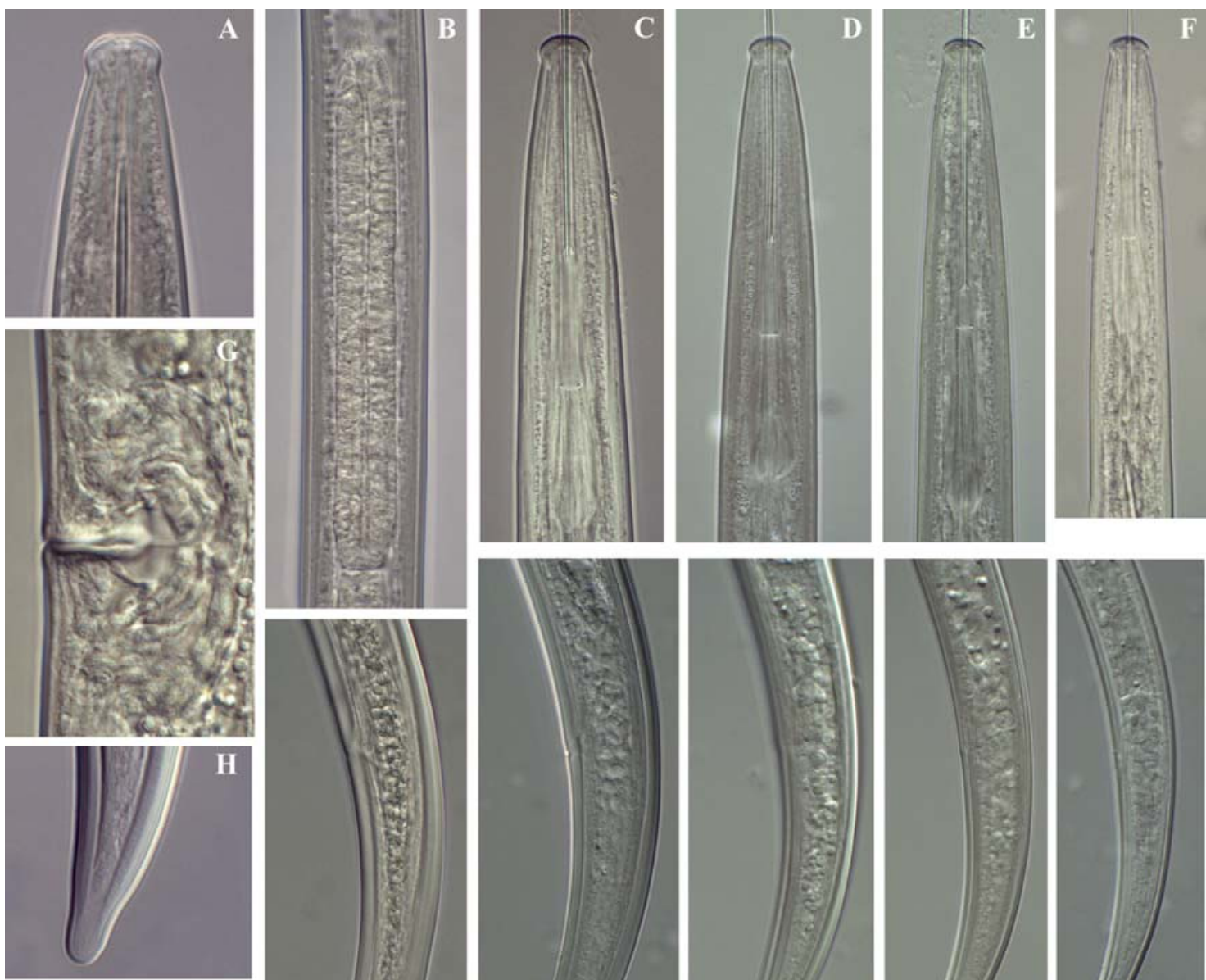

H
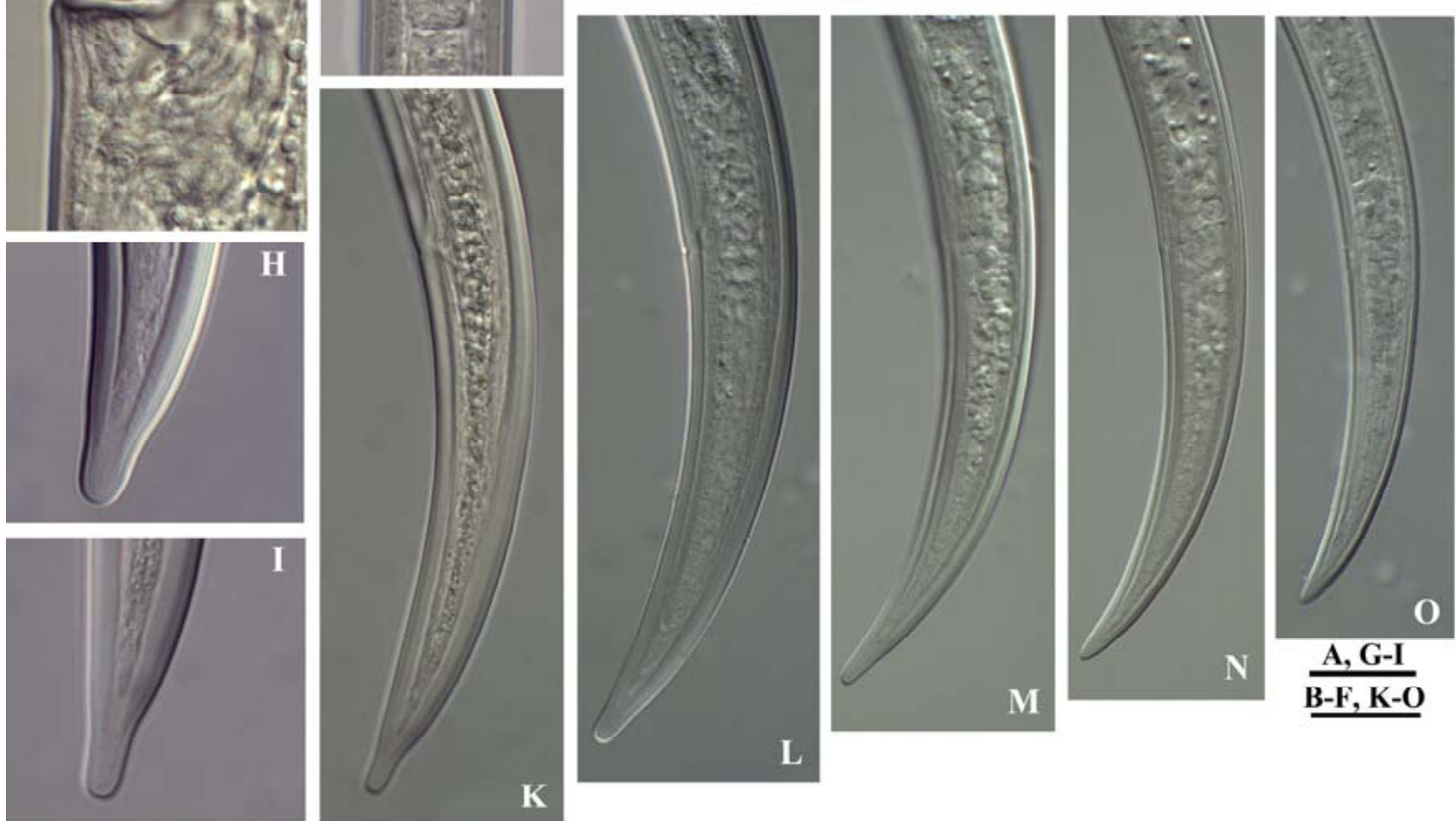

Fig. 4. Xiphinema italiae. Females and juveniles. A, Female head; B, Pharyngeal bulb; Anterior ends of female (C), fourth- to second-juvenile stages (D - F); G, Vagina; H, I, Tail tip variation; Tails of female (K, L), fourth- to second-juvenile stages (M - O); A, B, I, K - Adamclisi;

$$
\text { C-H, L-O - Bîrlad; Scale bars: A - G, I: } 12 \mu \mathrm{m} \text {; B - F, K - O: } 20 \mu \mathrm{m} \text {. }
$$

Juveniles: The juveniles assigned to 4 stages (Fig. 2A), similar to the female in general appearance, smaller in size with the tail showing specific shape at different stages: in $\mathrm{J} 1$, J2 elongate conoid, ventrally arcuate; J3 dorsally convex conoid with subdigitate terminus; J4 dorsally convex conoid, digitate with ventral peg.

Locality and plant association

Soil around cherry trees from Voineşti locality (Dâmboviţa County).

Remarks

Morphometrics and morphology of this species have been in the focus of a great number of nematological studies during the years and it has been shown that $X$. diversicaudatum expressed a high morphological variability caused by its wide range and diversity of hosts and conditions it occurred (Brown \& Topham, 1985; Roca \& Bravo, 1997; Barsi \& Lamberti, 2000a). The morphometrics of the population from Voineşti in general agrees with those reported earlier from Romania (Romaşcu, 1981), however specimens from Voineşti differ in the smaller body size, and in the lower values of $\mathbf{a}$ and $\mathbf{c}$ indices. The specimens in the present study are characterised by its rather small size $(2.8,3.6 \mathrm{~mm})$. The odontostyle is shorter compared to the population of $X$. diversicaudatum from Britain (Goodey et al., 1960) and some Italian populations (Roca et al., 1988, Roca \& Lamberti, 1993) and is more similar to the most populations reported from other European countries, South Africa and USA (Thorne, 1939; Sturhan, 1963; Heyns \& Coomnas, 1984; Lamberti et al., 1999; Barsi \& Lamberti, 2000b; Kumari, 2006). The spicules are in the ranges reported for this species except for the specimens from Bulgaria (Peneva \& Choleva, 1992) characterised with the shortest spicules recorded so far. Our observations on the juvenile stages confirmed the findings of Barsi and Lamberti (2000a) concerning the tail shape of the second stage juvenile - dorsally convex conoid (following the 
nomenclature by Coomans et al., 2001) in British population and elongate conoid in our population and previously reported data on juvenile stages from Serbia and Czech Republic (Barsi \& Lamberti, 2000b, Kumari, 2006). It is worth mentioning that the second stage juvenile has longer tail compared to other stages and adults in above mentioned populations, not so in those from Britain (Goodey et al., 1960), which also is specific in its great body and odontostyle size.

Xiphinema diversicaudatum occurs both in cultivated soils and natural habitats and has been reported from different crops (Pitcher et al., 1974), in particular, vineyards (Lišková, 1997; Barsi \& Lamberti, 2000b), orchards
(Lišková, 1995), rhizosphere of walnut trees (Lišková \& Brown, 1998) and forests (Lišková \& Brown, 1999; Lišková \& Sturhan, 2000), forest nurseries (Peneva \& Choleva, 1992), grassland of fluvial plains and river banks (Lišková, 2001) and from wild growing grapevine (Tiefenbrunner \& Tiefenbrunner, 2004). Xiphinema diversicaudatum is widespread in Europe, and has also been recorded from other temperate regions of the world, New Zealand, Australia, etc., most probably as a result of introduction (Pitcher et al., 1974, Brown \& Topham, 1985; Sturhan et al., 1997; Taylor \& Brown, 1997; Coomans et al., 2001, CAB International Distribution Maps of Plant Diseases, 2001).

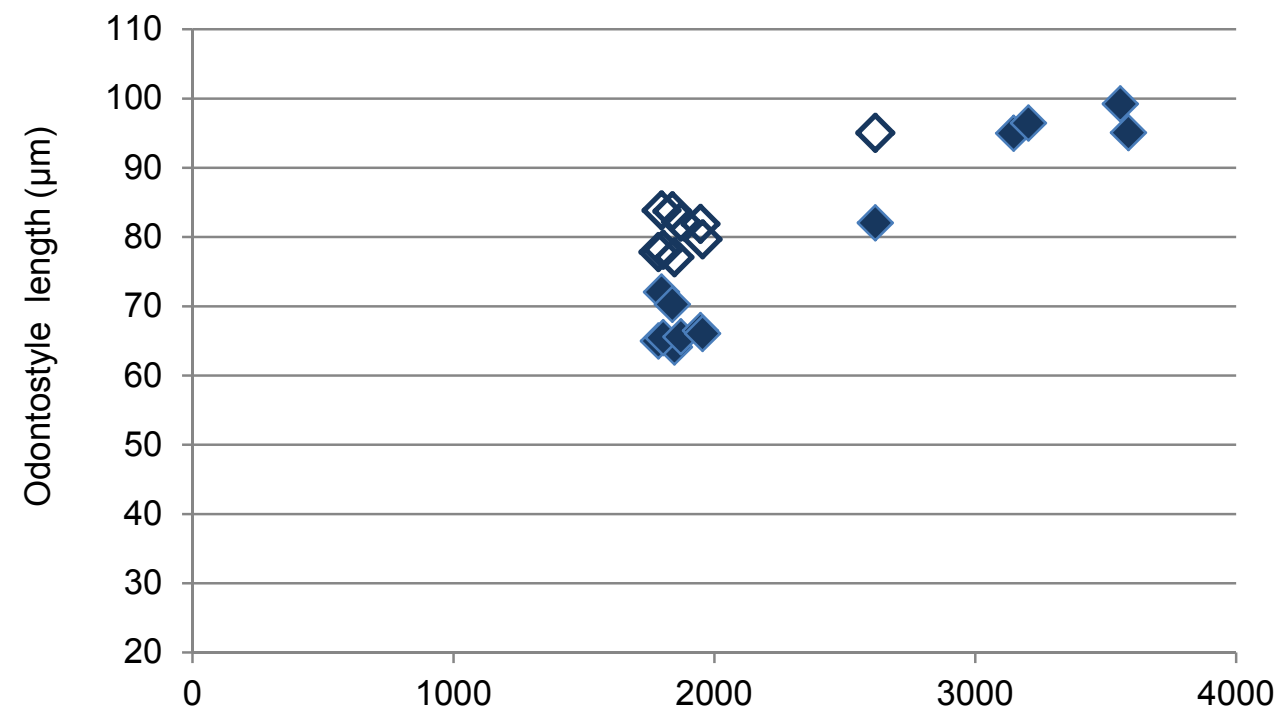

A

Body length $(\mu \mathrm{m})$

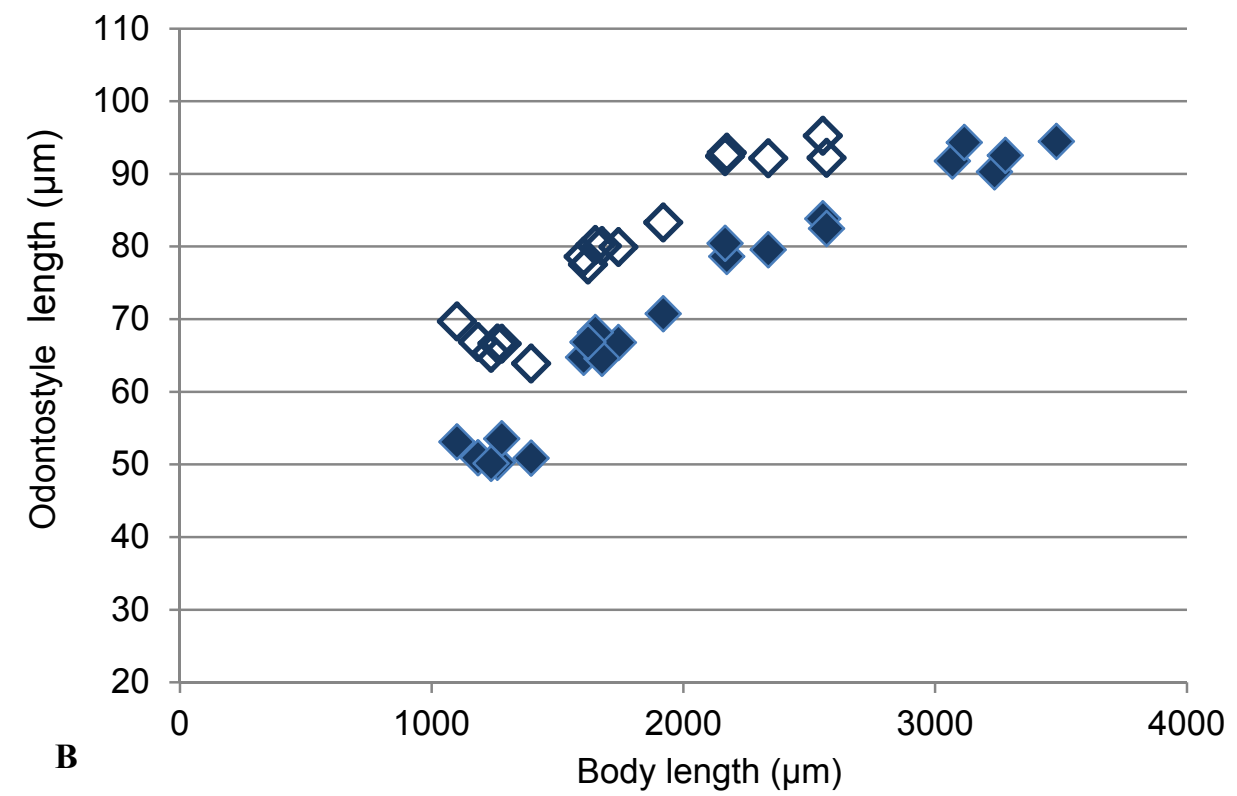

Fig. 5. Xiphinema italiae. Scatter plot of the functional $(\diamond)$ and replacement $(\diamond)$ odontostyle in relation to body length of the juvenile stages 
Xiphinema index Thorne \& Allen 1950 (Figs 2B and 3) Measurements

See Table. 2.

Description

Females. Body assuming an open $\mathrm{C}$-shape when heat relaxed; lip region continuous with the neck contour or set off by a slight depression; amphidial apertures almost as broad as head; Cuticle at postlabial region $3 \mu \mathrm{m}$; at midbody $3 \mu \mathrm{m}$, on tail posterior to anus $4.5 \mu \mathrm{m}$; uterus bipar- tite, pharyngeal bulb $105-116.5 \mu \mathrm{m}$ long. Uteri bipartite without $\mathrm{Z}$ differentiation, prerectum $342-466 \mu \mathrm{m}$ long; rectum $36.5-38 \mu \mathrm{m}$ long, tail dorsally convex conoid with a ventral peg $(9-10 \mu \mathrm{m})$ slightly variable in shape, caudal cuticle radially striated, $1-3$ caudal pores present.

Male. Very rare. Cuticle at postlabial region $3 \mu \mathrm{m}$; at midbody $4 \mu \mathrm{m}$ on tail posterior to anus $5 \mu \mathrm{m}$, spicules strong, $69 \mu \mathrm{m}$ long, arcuate; ventromedian supplements $1+3$; ventral peg $11 \mu \mathrm{m}$ long.

Table 3. Measurements of females and juvenile stages of Xiphinema italiae from Adamclisi and Bîrlad (mean \pm standard deviation, with range). All measurements in micrometers except $\mathrm{L}$ in $\mathrm{mm}$.

\begin{tabular}{|c|c|c|c|c|c|c|c|}
\hline \multirow[b]{2}{*}{ Character } & \multicolumn{3}{|c|}{ Adamclisi } & \multicolumn{4}{|c|}{ Bîrlad } \\
\hline & Females & $\mathbf{J 3}$ & $\mathbf{J} 4$ & Females & $\mathbf{J} 2$ & $\mathbf{J 3}$ & $\mathbf{J 4}$ \\
\hline $\mathrm{n}$ & $\mathrm{n}=4$ & $\mathrm{n}=7$ & $\mathrm{n}=1$ & $\mathrm{n}=5$ & $\mathrm{n}=5$ & $\mathrm{n}=6$ & $\mathrm{n}=5$ \\
\hline \multirow{2}{*}{$\mathrm{L}$} & $3.37 \pm 0.23$ & $1.86 \pm 0.65$ & \multirow{2}{*}{2.62} & $3.24 \pm 0.16$ & $1.27 \pm 0.78$ & $1.70 \pm 0.12$ & $2.36 \pm 0.20$ \\
\hline & $3.15-3.59$ & $1.79-1.96$ & & $3.07-3.48$ & $1.18-1.40$ & $1.60-1.92$ & $2.17-2.57$ \\
\hline \multirow{2}{*}{$\mathrm{a}$} & $102.8 \pm 10.0$ & $78.2 \pm 6.8$ & \multirow{2}{*}{95.2} & $95.9 \pm 7.3$ & $65.1 \pm 2.2$ & $79.1 \pm 7.2$ & $88.3 \pm 5.3$ \\
\hline & $88.3-109.9$ & $69.6-89.0$ & & $88.4-104.5$ & $62.8-68.4$ & $70.7-88.8$ & $83.3-97,1$ \\
\hline \multirow{2}{*}{$\mathrm{b}$} & $8.3 \pm 1.3$ & $6.0 \pm 0.3$ & \multirow{2}{*}{7.3} & $9.1 \pm 0.6$ & $5.3 \pm 0.6$ & $5.6 \pm 0.5$ & $7.0 \pm 0.5$ \\
\hline & $6.9-9.3$ & $5.6-6.4$ & & $8.5-9.9$ & $4.7-6.3$ & $4.6-6.0$ & $6.5-7.5$ \\
\hline \multirow[b]{2}{*}{ c } & $35.8 \pm 1.6$ & $23.2 \pm 1.9$ & \multirow{2}{*}{28.0} & $34.8 \pm 2.7$ & $19.1 \pm 1.2$ & $20.9 \pm 1.7$ & $26.6 \pm 2.1$ \\
\hline & $33.9-37.8$ & $20.6-26.2$ & & $32.2-38.9$ & $17.5-20.6$ & $18.6-23.1$ & $24.3-29.2$ \\
\hline \multirow{2}{*}{$c^{\prime}$} & $5.9 \pm 1.3$ & $5.0 \pm 0.6$ & \multirow{2}{*}{4.8} & $4.4 \pm 0.5$ & $5.1 \pm 0.4$ & $5.4 \pm 0.5$ & $4.9 \pm 0.3$ \\
\hline & $4.4-7.4$ & $4.3-5.7$ & & $3.8-5.0$ & $4.6-5.7$ & $4.6-6.0$ & $4.5-5.2$ \\
\hline \multirow{2}{*}{ V (\%) } & $46.8 \pm 0.6$ & & & $46.2 \pm 1.7$ & & & \\
\hline & $46.1-47.3$ & & & $44.7-48.1$ & & & \\
\hline \multirow{2}{*}{ G1 (\%) } & $8.5 \pm 1.0$ & & & $8.1 \pm 0.3$ & & & \\
\hline & $7.8-10.0$ & & & $7.7-8.5$ & & & \\
\hline \multirow{2}{*}{$\mathrm{G} 2(\%)$} & $9.1 \pm 2.2$ & & & $7.3 \pm 0.8$ & & & \\
\hline & $7.4-12.0$ & & & $6.4-8.3$ & & & \\
\hline \multirow{2}{*}{$\mathrm{d}$} & $8.1 \pm 0.3$ & $6.8 \pm 0.4$ & \multirow{2}{*}{7.3} & $7.1 \pm 0.2$ & $5.4 \pm 0.5$ & $6.7 \pm 0.4$ & $7.1 \pm 0.2$ \\
\hline & $7.8-8.6$ & $6.3-7.2$ & & $6.8-7.2$ & $4.8-5.9$ & $6.3-7.5$ & $6.9-7.3$ \\
\hline \multirow{2}{*}{$\mathrm{d}^{\prime}$} & $2.4 \pm 0.1$ & $2.1 \pm 0.1$ & \multirow{2}{*}{2.2} & $2.2 \pm 0.1$ & $1.9 \pm 0.1$ & $2.1 \pm 0.1$ & $2.2 \pm 0.0$ \\
\hline & $2.2-2.5$ & $2.1-2.2$ & & $2.1-2.3$ & $1.9-2.0$ & $2.0-2.3$ & $2.1-2.2$ \\
\hline \multirow{2}{*}{ Anterior end to guide ring } & $81.7 \pm 4.0$ & $58.1 \pm 3.3$ & 69 & $75.4 \pm 2.6$ & $41.9 \pm 3.7$ & $56.3 \pm 4.1$ & $65.6 \pm 2.2$ \\
\hline & $78-87.5$ & $52-63$ & 09 & $73-78$ & $37-45$ & $51-64$ & $63-69$ \\
\hline Odontostvle & $96.4 \pm 2.0$ & $66.9 \pm 2.8$ & 82 & $92.7 \pm 1.8$ & $51.1 \pm 1.4$ & $67.0 \pm 2.3$ & $81.0 \pm 2.1$ \\
\hline Udontostyle & $95-99$ & $64-72$ & 82 & $90-94.5$ & $50-53.5$ & $65-71$ & $79-84$ \\
\hline Replacement odontostyle & & $80.6 \pm 2.7$ & 95 & & $65.9 \pm 1.3$ & $79.9 \pm 2.0$ & $93.0 \pm 1.3$ \\
\hline & & $77-84$ & 95 & & $64-67$ & $78-83$ & $92-95$ \\
\hline Odontophore & $61.4 \pm 0.8$ & $47.7 \pm 1.8$ & 55 & $60.1 \pm 1.8$ & $41.5 \pm 0.6$ & $47.5 \pm 2.0$ & $52.6 \pm 1.3$ \\
\hline Uavilopilote & $60-62$ & $45-50$ & & $58-62$ & $40.5-42$ & $45-50$ & $51-55$ \\
\hline Pharvnx length & $400.5 \pm 48.5$ & $310.5 \pm 12.2$ & 360 & $357.9 \pm 9.9$ & $241.6 \pm 30.2$ & $311.5 \pm 34.1$ & $337.8 \pm 7.2$ \\
\hline Pnarynx rengtn & $363-455$ & $293.5-328$ & 500 & $344-366$ & $189-267$ & $274-362$ & $332-348$ \\
\hline Tail & $94.3 \pm 7.8$ & $80.6 \pm 6.6$ & 04 & $93.6 \pm 9.3$ & $66.8 \pm 3.3$ & $82.7 \pm 5.4$ & $88.6 \pm 2.6$ \\
\hline la1l & $88-105$ & $71-89$ & 94 & $84-108$ & $63-70.5$ & $75-89$ & $85-92$ \\
\hline Hyoline nort of toil & $10.0 \pm 1.3$ & $7.2 \pm 0.7$ & 8 & $9.7 \pm 0.8$ & $5.6 \pm 0.9$ & $7.1 \pm 1.2$ & $7.6 \pm 1,1$ \\
\hline Hyame part of tall & $9-11$ & $6-8$ & $\gamma$ & $8.5-11$ & $4-7$ & $6-9$ & $6.5-9$ \\
\hline Body diameter at: & $10.0 \pm 0.6$ & $8.6 \pm 0.3$ & 0 & $10.7 \pm 0.3$ & $7.9 \pm 0.4$ & $8.4 \pm 0.2$ & $9.2 \pm 0.1$ \\
\hline - lip region & $9.5-11$ & $8-9$ & 9 & $10-11$ & $7-8$ & $8-9$ & $9-9$ \\
\hline _ ouide rino & $24.2 \pm 0.3$ & $18.3 \pm 0.6$ & 21 & $23.4 \pm 0.9$ & $15.3 \pm 0.5$ & $17.8 \pm 1.0$ & $20.0 \pm 0.6$ \\
\hline - guide & $24-24.5$ & $17-19$ & 2 & $22-25$ & $14.5-16$ & $16-19$ & $19-20$ \\
\hline 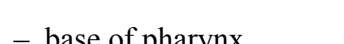 & $29.2 \pm 2.4$ & $23.5 \pm 2.4$ & 27 & $30.5 \pm 2.6$ & $19.1 \pm 0.6$ & $22.0 \pm 1.5$ & $25.6 \pm 1.4$ \\
\hline - base or pharynx & $26-32$ & $20-27$ & 21 & $29-35$ & $18-20$ & $20-24$ & $24-28$ \\
\hline - mid-hodv/at vulva & $32.9 \pm 2.0$ & $24.0 \pm 2.9$ & & $33.8 \pm 1.7$ & $19.5 \pm 1.7$ & $21.9 \pm 2.1$ & $26.8 \pm 2.3$ \\
\hline - mid-oody/al vuiva & $31-36$ & $20-28$ & & $31.5-36$ & $18-22$ & $19-24$ & $24-29.5$ \\
\hline an & $20.8 \pm 0.8$ & $16.1 \pm 1.9$ & 20 & $21.5 \pm 0.8$ & $13.2 \pm 1.0$ & $15.3 \pm 0.8$ & $18.1 \pm 1.3$ \\
\hline IS & $20-22$ & $14-19$ & 20 & $21-22.5$ & $12-15$ & $14-16$ & $16-20$ \\
\hline ine nart & $6.7 \pm 0.6$ & $4.3 \pm 0.4$ & 6 & $6.8 \pm 0.8$ & $4.1 \pm 0.3$ & $4.1 \pm 0.3$ & $4.4 \pm 0,6$ \\
\hline - ny & $6-7.5$ & $4-5$ & 0 & $6-8$ & $3.5-4$ & $4-5$ & $4-5$ \\
\hline
\end{tabular}


Juveniles: All four stages present (Fig. 2B). Body posture less ventrally curved, than in adults, smaller in size with tail showing specific shape at different stages (elongate conoid more or less straight in first and second stages juveniles, dorsally convex conoid with subdigitate terminus in third stage and dorsally convex conoid, digitate with ventral peg in fourth stage juveniles).

Locality and plant association

Vineyard soil from Valea Călugărească (Prahova County). Remarks

Compared to the type population (Siddiqi, 1974) Romanian specimens are charcterised by a shorter body (av. 2.8 $(2.7-2.9) \mathrm{mm} v s$ av. $3.1(2.91-3.28 \mathrm{~mm})$ and more posteriorly situated vulva (av. $\mathrm{V}=42.9(41-45)$ vs av. $\mathrm{V}=$ $39.4(38-40)$. The species has been reported mainly from vineyards but also in association with fig tree, roses, mulberry, citruses and riparian vegetation (Siddiqi, 1974;
Lamberti et al., 1983, Ivezic et al., 2002; Magunacelaya et al., 2004; Jawhar et al., 2006; Tzortzakakis et al.; 2006, Lazarova et al., 2010) and there are numerous studies on its association with grapevine viruses (Avgelis \& Tzortzakakis, 2001). The world distribution of $X$. index is closely related to that of its most important host, grapevine: Europe, Israel, Middle East, North and South Africa, USA, Mexico, South America (Siddiqi, 1974; Taylor \& Brown, 1997; CAB International Distribution Maps of Plant Diseases, 2000, map 819; Coomans et al., 2001).

Xiphinema italiae Meyl, 1953 (Figs 4 and 5)

Measurements

See Table. 3.

Description

Females. Body slender. Lip region gently rounded, set off by constriction. Cuticle at postlabial region $1-1.5 \mu \mathrm{m}$, at
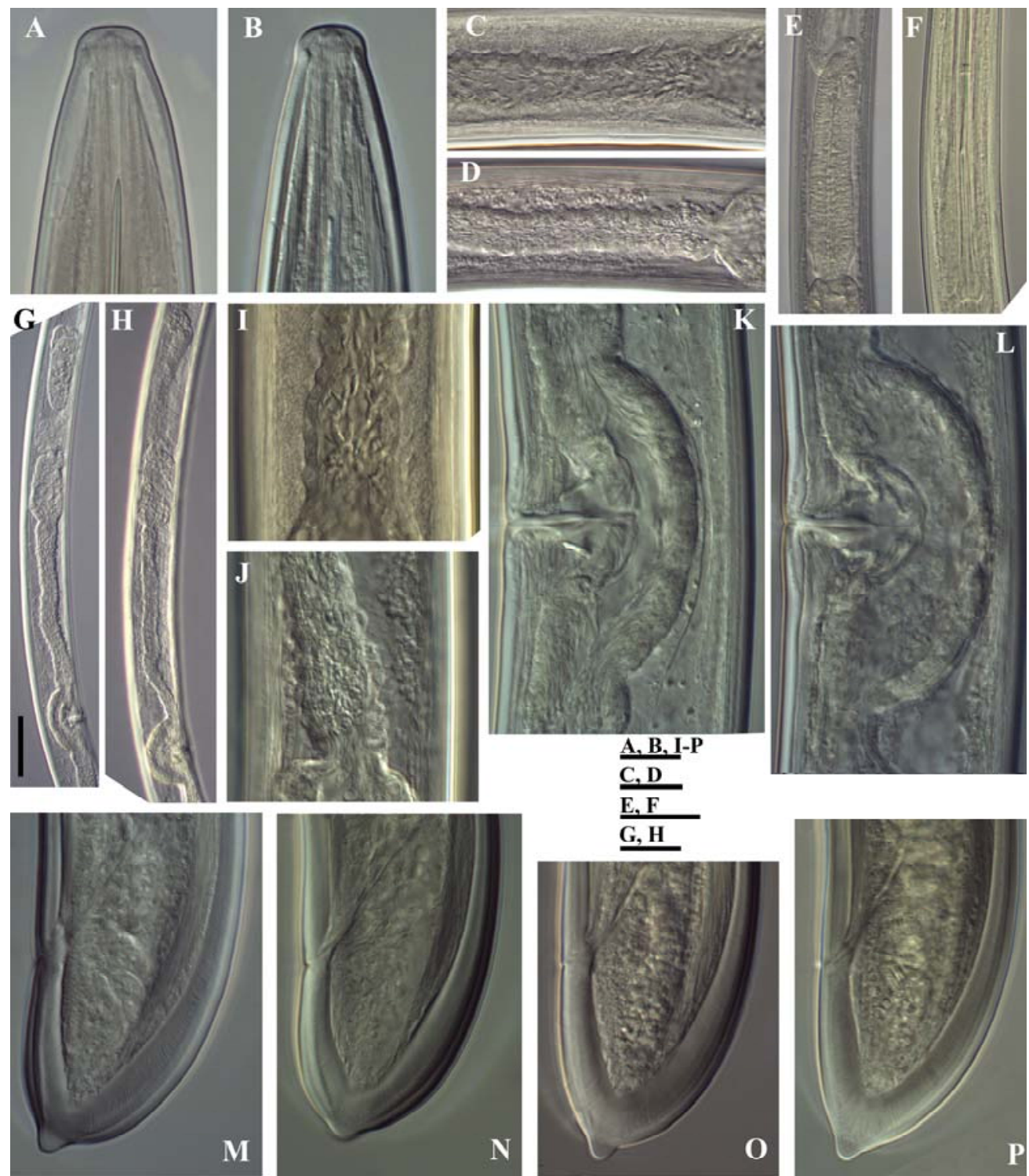

Fig. 6. Xiphinema vuittenezi. Females. A, B, Anterior end; C, D, tubular part of uterus with uterine spines; E, Pharyngeal bulb; F, Odontophore and part of odontostyle, G, H, Anterior genital branch; I, J, uterine spines; K, L, Vaginal region; M-P, Variations in tail shape. A, C, E, F, I, G, K, M, N-Murfatlar; B, D, H, J, L, O, P-Ostrov. Scale bars: A,B, I- P: $12 \mu \mathrm{m}$; C, D: $20 \mu \mathrm{m}$; E, F: $40 \mu \mathrm{m}$; G, H: $60 \mu \mathrm{m}$. 

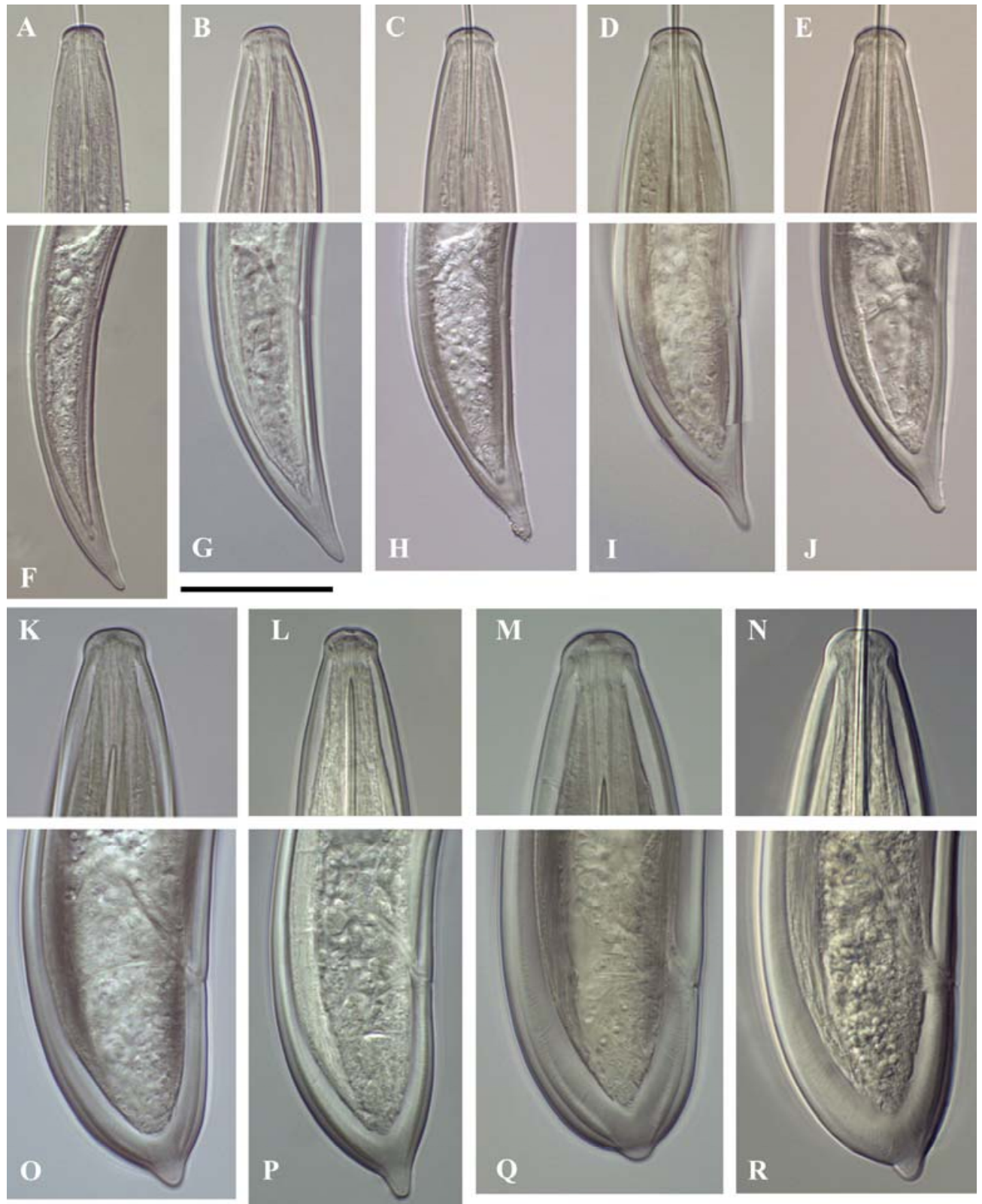

Fig. 7. Xiphinema vuittenezi. Juvenles. A - E, K-N, Head ends of first- to fourth-stages and females of both populations; $\mathrm{F}-\mathrm{J}, \mathrm{O}-\mathrm{R}, \mathrm{Tails}$ of first- to fourth- juvenile stages and females of both populations; A, B, D, F, G, I, K, M-Murfatlar; C, E, H, J, L, N - Ostrov. Scale-bar: $30 \mu \mathrm{m}$.

mid-body $1.5-2.5 \mu \mathrm{m}$, on tail posterior to anus $3-3.5 \mu \mathrm{m}$. Genital system amphidelphic with equally developed gonads and reflexed ovaries, uteri bipartite, without Z-differentiation. Tail shape commonly elongate-conoid with slight dorsal or/and ventral constrictions towards the terminus, sometimes bluntly conoid, and even almost subdigitate.

Juveniles. Three juvenile stages were present for Bîrlad (first stage juvenile missing) and two for Adamclisi populations (the first two stages not found).

Locality and habitat

Vineyards in two region of the country: south-east (Adamclisi - Constanţa County) and east (around Bîrlad locality - Vaslui County).

\section{Remarks}

Xiphinema italiae is known as a Mediterranean dagger nematode and its range include Mediterranean and some
Southeastern European countries, also Nigeria, South Africa, Seychelles, Cuba, Turkey, primarily associated with grapevine but also found in the rhizosphere of different fruit trees, olive, conifers, natural vegetation etc (Cohn, 1977; Coomans et al., 2001; CAB International, 2001).

Xiphinema vuittenezi Luc, Lima, Weischer \& Flegg, 1964 (Figs 6-8)

Measurements

See Table 4 and 5.

Description

Females. Body arcuate, especially in posterior part, cuticle with distinct outer layer, lip region set off by a slight depression from the rest of the body, amphidial aperture almost as broad as lip region; genital tract with two well developed branches, uterus tripartite, $\mathrm{Z}$ differentiation in 
the form of small globular bodies and spindle-like uterine spines, sometimes quadric in shape refractive structures observed at the proximal par of tubular region of uterus; tail rounded, ending in a short terminal peg $3-4 \mu \mathrm{m}$ long, sometimes the peg has a reduced length.

Juveniles Four stages present (Fig. 8). Similar to the female, body posture less ventrally curved, than in adults, smaller in size with tail showing specific shape at different stages (elongate-conoid in first stage juveniles and dorsaly convex conoid with digitated terminus in second, dorsaly convex conoid with central peg in third and fourth stages, the latter being most similar to female tail shape).

Locality and habitat

Murfatlar and Ostrov (Constanţa County), rhizosphere of grapevines.

Remarks

Populations of $X$. vuittenezi studied exhibited interpopulation variability concerning some morphological characters,

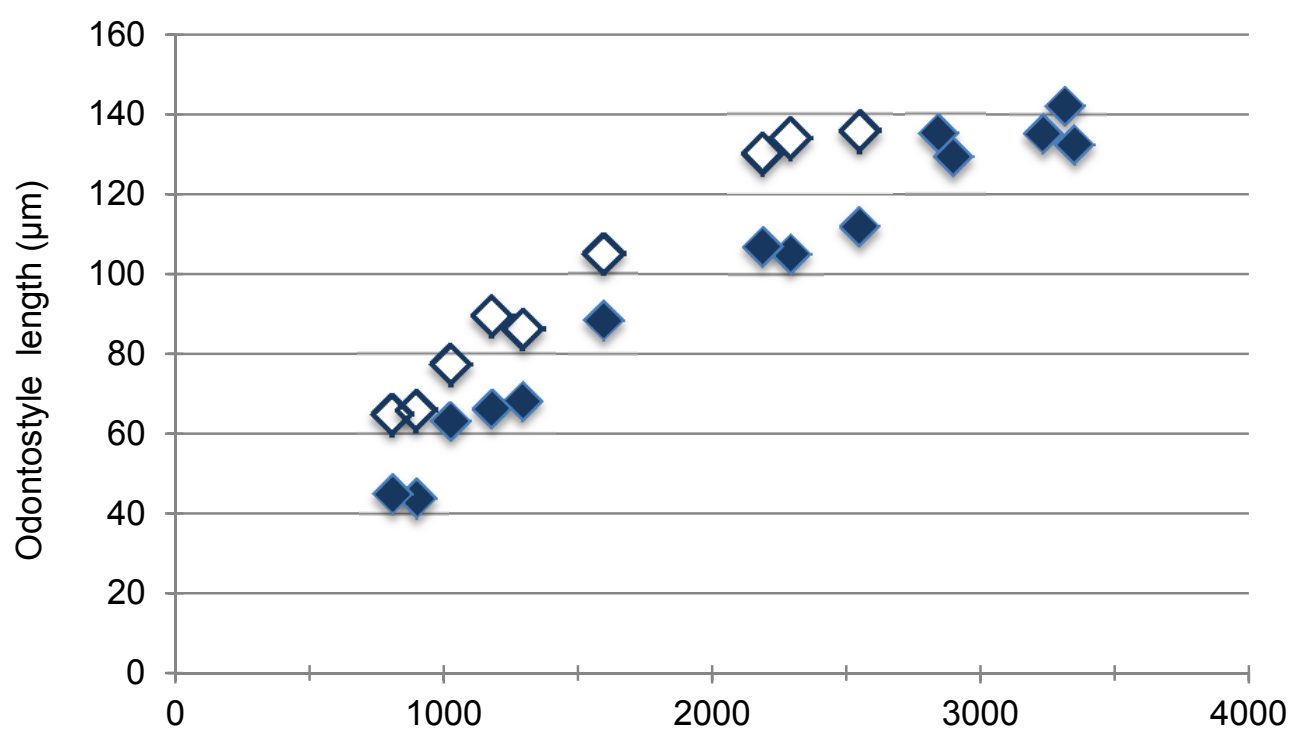

A

Body length $(\mu \mathrm{m})$

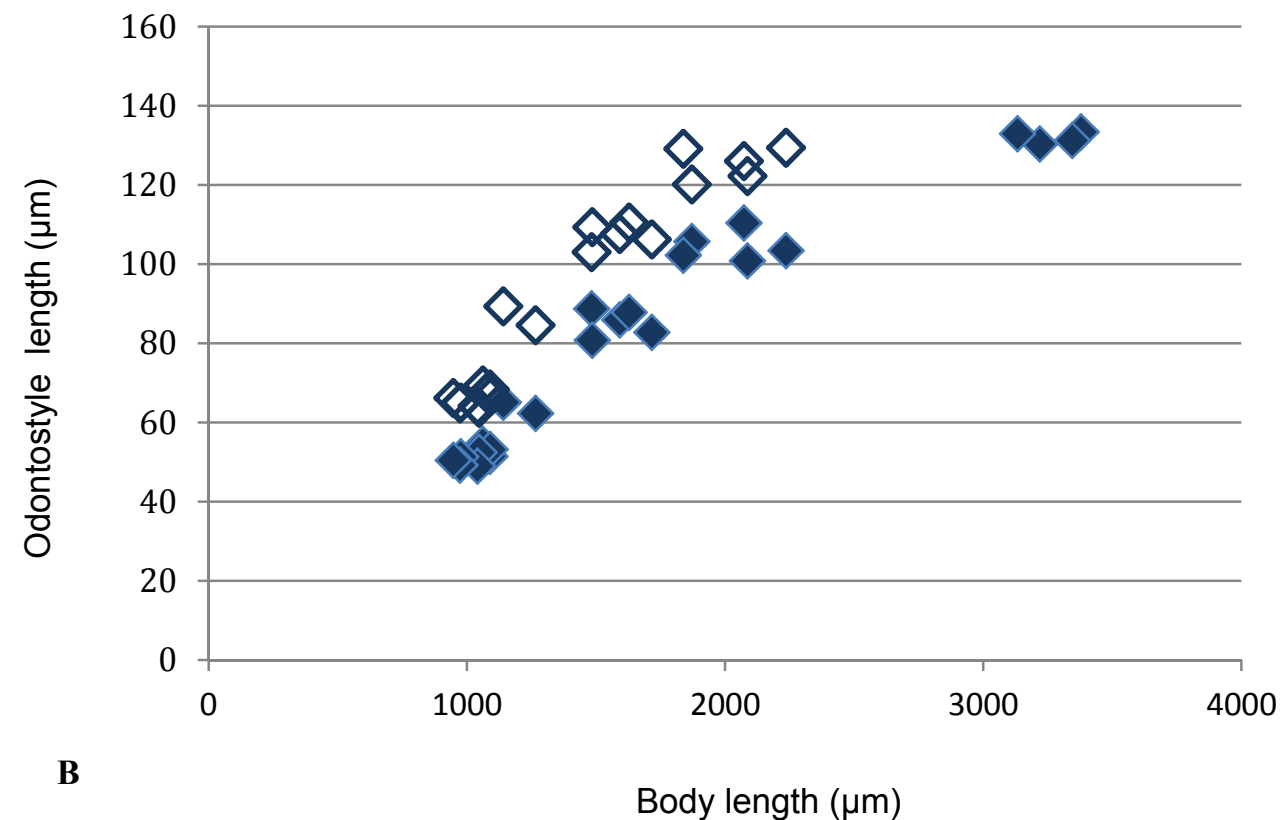

Fig. 8. Xiphinema vuttenezi. Scatter plot of the functional $(\diamond)$ and replacement $(\diamond)$ odontostyle in relation to body length of the juvenile stages and adults. A, Murfatlar B, Ostrov 
females from Ostrov have longer tail, lower c values, body width at beginning of hyaline part of tail smaller and more posteriorly situated vulva, compared with Murfatlar specimens. Further, the uterine spines are bigger and in a higher numbers in Murfatlar females, similar to those reported by Barsi and Lamberti (2000b), small globular bodies at the junction of pars dilalata and tubular part of uterus almost missing. In general $X$. vuittenezi females from two Romanian vineyards populations studied by Romaşcu and Zinca (1977) were similar to those reported here, only the recent specimens from Murfatlar had longer odontostyle and more antreiorly situated vulva; characters that are distinctive for this population; mean ranges for odontosyle of known $X$. vuittenezi populations from different regions and hosts varied between av. 120 and $132 \mu \mathrm{m}$ with total range of $111-140 \mu \mathrm{m} v s$ av. $135(129.5-142) \mu \mathrm{m}$ and vulva is situated around middle $v s \mathrm{~V}=46.4(44.5-47)$ (Luc et al., 1964; Roca et al., 1988, 1989, 1991; Lamberti et al., 1997, 1999; Barsi \& Lamberti, 2000b; Kumari, 2004). Only one population of $X$. vuittenezi originating from Italy (Coiro et al., 1989) has similar odontostyle length (135 $\mu \mathrm{m}$ (128 138) $\mu \mathrm{m})$.

Table 4. Measurements of females and juvenile stages of Xiphinema vuittenezi from Murfatlar, (mean \pm standard deviation, with range). All measurements in micrometers except $\mathrm{L}$ in $\mathrm{mm}$.

\begin{tabular}{|c|c|c|c|c|c|}
\hline Character & Females & $\mathbf{J 1}$ & $\mathbf{J} 2$ & $\mathbf{J 3}$ & J4 \\
\hline $\mathrm{n}$ & $\mathrm{n}=5$ & $\mathrm{n}=2$ & $\mathrm{n}=3$ & $\mathrm{n}=1$ & $\mathrm{n}=3$ \\
\hline $\mathrm{L}$ & $\begin{array}{c}3.13 \pm 0.24 \\
2.84-3.35\end{array}$ & 896,807 & $1290,1176,1024$ & 1594 & $2290,2547,2187$ \\
\hline a & $\begin{array}{c}61.1 \pm 4.3 \\
55.1-64.9\end{array}$ & $44.8,40.8$ & $41.3,42.9,42.5$ & 46.3 & $54.9,54.7,58.3$ \\
\hline $\mathrm{b}$ & $\begin{array}{l}7.0 \pm 0.5 \\
6.4-7.5\end{array}$ & $3.8,3.5$ & $4.5,3.9,3.7$ & 4.9 & $5.4,5.8,5.2$ \\
\hline $\mathrm{c}$ & $\begin{array}{c}98.6 \pm 7.7 \\
92.4-108.6\end{array}$ & $19.9,16.5$ & $27.3,22.7,22.9$ & 36.2 & $56.2,65.2,53.4$ \\
\hline$c^{\prime}$ & $\begin{array}{l}0.9 \pm 0.1 \\
0.8-1.0\end{array}$ & $3.8,3.6$ & $1.9,2.5,2.5$ & 1.8 & $1.2,1.1,1.2$ \\
\hline $\mathrm{V}(\%)$ & $\begin{array}{c}46.3 \pm 1.1 \\
44.5-47.4\end{array}$ & & & & \\
\hline G1 (\%) & $\begin{array}{c}13.9 \pm 1.2 \\
13.0-15.6\end{array}$ & & & & \\
\hline G2 (\%) & $\begin{array}{c}13.6 \pm 1.1 \\
12.2-15.3\end{array}$ & & & & \\
\hline d & $\begin{array}{l}9.8 \pm 0.9 \\
8.8-11.2\end{array}$ & 4.5 & $6.2,6.3,5.9$ & 8.4 & $8.3,8.1,8.2$ \\
\hline$d^{\prime}$ & $\begin{array}{l}2.9 \pm 0.2 \\
2.8-3.3\end{array}$ & 2.0 & $2.4,2.4,2.3$ & 3.0 & $2.7,2.8,2.7$ \\
\hline Anterior end to guide ring & $\begin{array}{c}128.3 \pm 2.7 \\
124-131\end{array}$ & 38,37 & $59,60,54$ & 75 & $102,99,99$ \\
\hline Odontostyle & $\begin{array}{l}135.0 \pm 5.4 \\
129.5-142\end{array}$ & 44,45 & $68,66,63$ & 88.5 & $105,112,107$ \\
\hline Replacement odontostyle & & 66,65 & $86,90,77.5$ & 105 & $134,136,130$ \\
\hline Odontophore & $\begin{array}{c}80.6 \pm 2.2 \\
78-83\end{array}$ & 37,38 & $50,51,47$ & 57 & $70,71,68$ \\
\hline Pharynx length & $\begin{array}{l}449.7 \pm 20.3 \\
429.5-477\end{array}$ & 235,230 & $287,303,273$ & 325.5 & $424,440.5,418$ \\
\hline Tail & $\begin{array}{l}32.5 \pm 2.6 \\
30-36\end{array}$ & 45,49 & $47,52,45$ & 44 & $41,39,41$ \\
\hline Hyaline part of tail & $\begin{array}{c}11.6 \pm 0.9 \\
10-13\end{array}$ & $10.2,8.9$ & $15,13,13$ & 14 & $11.5,15,14$ \\
\hline $\begin{array}{l}\text { Body diameter at: } \\
\text { - lip region }\end{array}$ & $\begin{array}{l}13.2 \pm 1.4 \\
11-15\end{array}$ & $8.4,8.3$ & $9.5,10,9$ & 9 & $12,12,12$ \\
\hline - guide ring & $\begin{array}{c}38.7 \pm 1.9 \\
37-41\end{array}$ & $17,16.8$ & $23,23,21$ & 26 & $33,34,32$ \\
\hline - base of pharynx & $\begin{array}{c}43.7 \pm 0.9 \\
42-44\end{array}$ & $19.2,19$ & $30,26,23$ & 31 & $40,42,37$ \\
\hline - mid-body/at vulva & $\begin{array}{l}51.1 \pm 0.7 \\
50-52\end{array}$ & $20,19.8$ & $31,27,24$ & 34.5 & $42,46.5,37.5$ \\
\hline- anus & $\begin{array}{c}37.0 \pm 3.4 \\
31-39\end{array}$ & $11.9,13.5$ & $25,21,18$ & 25 & $35,36,33.5$ \\
\hline - hyaline part & $\begin{array}{l}26.4 \pm 1.8 \\
25-29.5\end{array}$ & $5.5,5.2$ & $10,8,7$ & 10 & $20,24,19$ \\
\hline
\end{tabular}


Table 5. Measurements of females and juvenile stages of Xiphinema vuittenezi from Ostrov, (mean \pm standard deviation, with range). All measurements in micrometers except $\mathrm{L}$ in $\mathrm{mm}$.

\begin{tabular}{|c|c|c|c|c|c|}
\hline Character & Females & J1 & $\mathrm{J} 2$ & J3 & J4 \\
\hline $\mathrm{n}$ & $\mathrm{n}=4$ & $\mathrm{n}=8$ & $\mathrm{n}=2$ & $\mathrm{n}=5$ & $\mathrm{n}=5$ \\
\hline \multirow[t]{2}{*}{$\mathrm{L}$} & $3.24 \pm 0.14$ & $1.03 \pm 0.56$ & $1.27,1.14$ & $1.58 \pm 0.99$ & $2.02 \pm 1.66$ \\
\hline & $3.11-3.38$ & $0.95-1.09$ & & $1.48-1.72$ & $1.84-2.24$ \\
\hline \multirow[t]{2}{*}{$\mathrm{a}$} & $64.5 \pm 1.0$ & $46.1 \pm 2.7$ & $43.2,43.8$ & $48.6 \pm 0.6$ & $54.4 \pm 3.5$ \\
\hline & $63.5-65.5$ & $41.7-49.6$ & & $48.0-49.6$ & $51-59$ \\
\hline \multirow[t]{2}{*}{ b } & $6.8 \pm 0.7$ & $4.2 \pm 0.2$ & $4.5,4.2$ & $4.7 \pm 0.4$ & $5.2 \pm 0.6$ \\
\hline & $6.0-7.2$ & $3.8-4.5$ & & $4.2-5.2$ & $4.3-5.7$ \\
\hline \multirow[t]{2}{*}{$\mathrm{c}$} & $88.7 \pm 2.5$ & $17.9 \pm 1.2$ & $28.8,26.8$ & $35.6 \pm 3.0$ & $49.3 \pm 5.8$ \\
\hline & $85.2-91.0$ & $16.1-20.0$ & & $31.9-38.9$ & $44.5-56.1$ \\
\hline \multirow[t]{2}{*}{$c^{\prime}$} & $1.0 \pm 0.0$ & $3.8 \pm 0.4$ & $2.2,2.2$ & $1.8 \pm 0.1$ & $1.4 \pm 0.1$ \\
\hline & $1.0-1.0$ & $3.2-4.4$ & & $1.6-1.9$ & $1.3-1.4$ \\
\hline \multirow[t]{2}{*}{ V $(\%) /$} & $49.6 \pm 1.0$ & & & & \\
\hline & $48.5-50.8$ & & & & \\
\hline \multirow[t]{2}{*}{ G1 (\%) } & $14.2 \pm 2.6$ & & & & \\
\hline & $12.5-18.0$ & & & & \\
\hline \multirow[t]{2}{*}{ G2 (\%) } & $14.1 \pm 2.1$ & & & & \\
\hline & $12.3-16.9$ & & & & \\
\hline \multirow[t]{2}{*}{$d$} & $8.8 \pm 0.9$ & $5.1 \pm 0.3$ & $5.5,6.0$ & $6.7 \pm 0.8$ & $7.0 \pm 0.8$ \\
\hline & $8.0-9.6$ & $4.6-5.6$ & & $5.6-7.4$ & $6.2-8.1$ \\
\hline \multirow[t]{2}{*}{$\mathrm{d}^{\prime}$} & $2.8 \pm 0.1$ & $2.1 \pm 0.1$ & $2.4,2.2$ & $2.6 \pm 0.2$ & $2.7 \pm 0.1$ \\
\hline & $2.7-2.9$ & $2.0-2.3$ & & $2.4-2.9$ & $2.5-2.8$ \\
\hline \multirow[t]{2}{*}{ Anterior end to guide ring } & $115.8 \pm 12.0$ & $39.8 \pm 1.9$ & 47,54 & $66.4 \pm 8.9$ & $73.6 \pm 10.2$ \\
\hline & $102-128$ & $37-42$ & & $55-78$ & $61-87$ \\
\hline \multirow[t]{2}{*}{ Odontostyle } & $132.0 \pm 1.4$ & $51.4 \pm 1.9$ & 62,65 & $85.2 \pm 3.4$ & $104.5 \pm 3.8$ \\
\hline & $130-133$ & $49-54.5$ & & $81-89$ & $101-110$ \\
\hline \multirow[t]{2}{*}{ Replacement odontostyle } & & $66.0 \pm 2.0$ & 85,89 & $107.3 \pm 2.9$ & $125.4 \pm 4.1$ \\
\hline & & 64-69 & & $103-110.5$ & $120-129$ \\
\hline \multirow[t]{2}{*}{ Odontophore } & $77.1 \pm 4.4$ & $37.5 \pm 2.2$ & 48,50 & $57.9 \pm 0.7$ & $66.9 \pm 2.2$ \\
\hline & $72-82.5$ & $34-42$ & & $57-59$ & $64-69$ \\
\hline \multirow[t]{2}{*}{ Pharynx length } & $480.7 \pm 51.0$ & $244.3 \pm 9.5$ & 279,274 & $337.7 \pm 32.2$ & $391.9 \pm 28.6$ \\
\hline & $438-537$ & $231-261$ & & $313-391$ & $366.5-439$ \\
\hline \multirow[t]{2}{*}{ Tail } & $36.8 \pm 1.0$ & $57.8 \pm 4.5$ & 44,43 & $44.6 \pm 2.7$ & $41.2 \pm 3.2$ \\
\hline & $35-38$ & $52-66$ & & $41-48$ & $37-46$ \\
\hline \multirow[t]{2}{*}{ Hyaline part of tail } & $12.9 \pm 1.0$ & $10.2 \pm 1.3$ & 13,11 & $13.0 \pm 1.1$ & $13.3 \pm 1.1$ \\
\hline & $11.5-14$ & $9-12$ & & $12-14.5$ & $12-14$ \\
\hline \multirow{4}{*}{$\begin{array}{l}\text { Body diameter at: } \\
\text { - lip region } \\
\text { - guide ring }\end{array}$} & $13.1 \pm 0.4$ & $7.8 \pm 0.2$ & 8,9 & $9.9 \pm 0.5$ & $11.4 \pm 0.4$ \\
\hline & $13-14$ & $7.5-8$ & & $9-10.5$ & $11-12$ \\
\hline & $37.3 \pm 0.7$ & $16.4 \pm 1.0$ & 20,20 & $25.4 \pm 1.0$ & $30.7 \pm 1.6$ \\
\hline & $36-38$ & $15-18$ & & $24-27$ & $29-33$ \\
\hline \multirow[t]{2}{*}{ - base of pharynx } & $44.2 \pm 0.5$ & $21.6 \pm 2.1$ & 26,24 & $31.2 \pm 1.2$ & $36.3 \pm 3.2$ \\
\hline & $43.5-45$ & $18-24$ & & $30-33$ & $34-42$ \\
\hline \multirow[t]{2}{*}{ - mid-body/at vulva } & $50.7 \pm 1.8$ & $22.4 \pm 2.2$ & 29,26 & $32.5 \pm 2.0$ & $36.8 \pm 1.5$ \\
\hline & $49-53$ & $19.5-25$ & & $31-35.5$ & $35-38$ \\
\hline \multirow[t]{2}{*}{- anus } & $37.3 \pm 0.5$ & $15.5 \pm 1.7$ & 20,19 & $24.7 \pm 0.6$ & $30.3 \pm 2.5$ \\
\hline & $37-38$ & $13-18$ & & $24-25$ & $28-34$ \\
\hline \multirow[t]{2}{*}{ - hyaline part } & $23.8 \pm 1.1$ & $6.0 \pm 0.3$ & 9,11 & $12.0 \pm 0.4$ & $17.4 \pm 1.7$ \\
\hline & $23-25$ & $5.5-6$ & & $11-12$ & $15-19$ \\
\hline
\end{tabular}

The present study of the Romanian populations is in agreement with the previous data for juvenile developmental stages as originally described by Luc et al. (1964) and confirmed by other authors (Barsi \& Lamberti, 2000b; Kumari, 2004). Xiphinema vuittenezi is recorded in association with grapevine, stonefruits, pomerfruits; the species is widely distributed in Europe, especially Central Europe; reported also from Iran; its occurrence in USA and Australia is probably a result of introduction (Brown \& Taylor, 1987; Coomans et al. 2001; Walker, 2004).
Diagnostics by multipex PCR

Overall, 24 multiplex PCR tests were performed for all studied populations ( 3 for $X$. diversicaudatum, $5-X$. index, $3-X$. vuittenezi from Murfatlar, $7-X$. vuittenezi from Ostrov, $2-X$. italiae from Adamclisi and $4-X$. italiae from Bîrlad). All tested populations were positive and the size of the fragments was constant within each Xiphinema species. Herein, a picture of one of the agarose gels with amplified PCR products from all four species is presented (Fig. 9). Single fragments of approximately 590, 340, 800 and 410 bp were amplified for $X$. vuittenezi (lanes 2-3, 


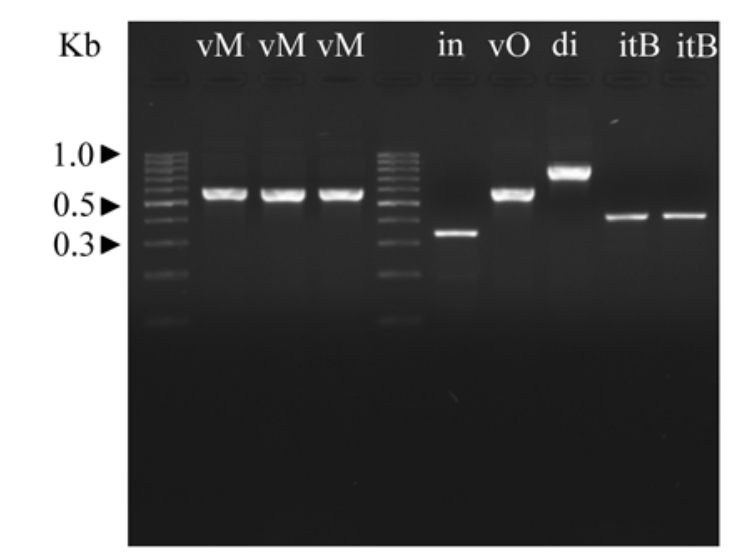

Fig. 9. Electrophoresis of the amplified DNA products in a multiplex test using sense and antisense species-specific primers designed by Wang et al. (2003). Lanes 1 and $5-1 \mathrm{~Kb}$ DNA ladder; $X$. vuittenezi: lanes $2-4$, Murfatlar (vM) and lane 7, Ostrov (vO); $X$. index: lane 5 (in); X. diversicaudatum: lane 8 (di); $X$. italiae: lanes 8 and 9 , Bîrlad (itB).

Murfatlar and 7, Ostrov), X. index (lane 5), X. diversicaudatum (lane 8 ) and $X$. italiae (lane 8 and 9, Bîrlad), respectively, that are in accordance to the study by Wang et al. (2003). The PCR products for both studied populations of $X$. vuittenezi and $X$. italiae were of the same size (data not shown for Adamclisi and Bîrlad populations of $X$. italiae).

\section{Sequencing and PCR-RFLP analyses}

Due to the morphometrical differences found between the two $X$. vuittenezi populations additional DNA analyses have been done only for this species. Amplification, RFLP and sequencing of two ribosomal gene domains (D2-D3 $28 \mathrm{~S}$ rDNA and ITS) and the levels of genetic variation were discussed. The PCR products of the D2-D3 and ITS (including the $3^{\prime}$ end of the $18 \mathrm{~S}$ and the $5^{\prime}$ end of the 28S) regions for both populations of $X$. vuittenezi were $840 \mathrm{bp}$ and $1810 \mathrm{bp}$, respectively.

Four different nucleotides (i.e. $0.5 \%$ dissimilarity) in D2D3 sequences between the two Romanian populations were detected and one to three (or less than $0.3 \%$ divergence) with the corresponding sequences of $X$. vuittenezi from Hungary (AY601614) and Czech Republic (EF614266) deposited in GenBank (He et al. 2005; Kumari et al., 2009). Similar low level of interpopulation genetic diversity $(<1.5 \%)$ was revealed for other Xiphinema nonamericanum group species such as $X$. index $(0-0.3 \%), X$. diversicaudatum $(0-0.8 \%$ and $X$. italiae $(0.3-1.4 \%$ GenBank accession numbers AY601613, FJ713153, HM921350, HM921351) (He et al., 2005; Kumari \& Lišková, 2009; Gutiérrez-Gutiérrez et al., 2011; Kumari \& Di Cesare, 2013). The ITS-RFLP analysis for both populations produced identical species-specific patterns that clearly identified $X$. vuittenezi from Romania (Fig. 10). Furthermore, these profiles were identical to those obtained for $X$. vuittenezi from Hungary (De Luca, pers. comm.) revealing that these profiles could be used for species diagnostic.

The ITS sequence divergence between both Romanian populations was of 11 nucleotides and two indels (or $0.6 \%$ dissimilarity). No complete ITS sequence of $X$. vuittenezi was found in the GenBank. However, 6 and 7 different nucleotides (or up to $0.6 \%$ divergence) between the Romanian ITS 1 and the corresponding region of $X$. vuittenez $i$ from Germany was detected, whereas 1 and 5 different bases (i.e. $0.2 / 0.8 \%$ ) in the ITS2 region compared with that from Czech Republic (Wang et al., 2003; Kumari et al., 2009). These analyses revealed again a comparatively low level of ITS intra-specific/interpopulation genetic variability that has been shown also for other studies on Xiphinema non-americanum group species (X. diversicaudatum GenBank accession numbers JQ780353 JQ780358 and X. index (AY584243, AY430175 JF437918 (Finetti-Sialer \& Ciancio, 2005; Meza et al., 2012, Kumari $\&$ Di Cesare, 2013). However, the pairwise comparison of the entire ITS region of $X$. vuittenezi from Romania with the corresponding region of $X$. vuittenezi from Hungary (De Luca, pers. comm.) showed 23 different nucleotides and 12 gaps suggesting a much higher intra-specific nucleotide variability among these populations of $X$. vuittenezi.

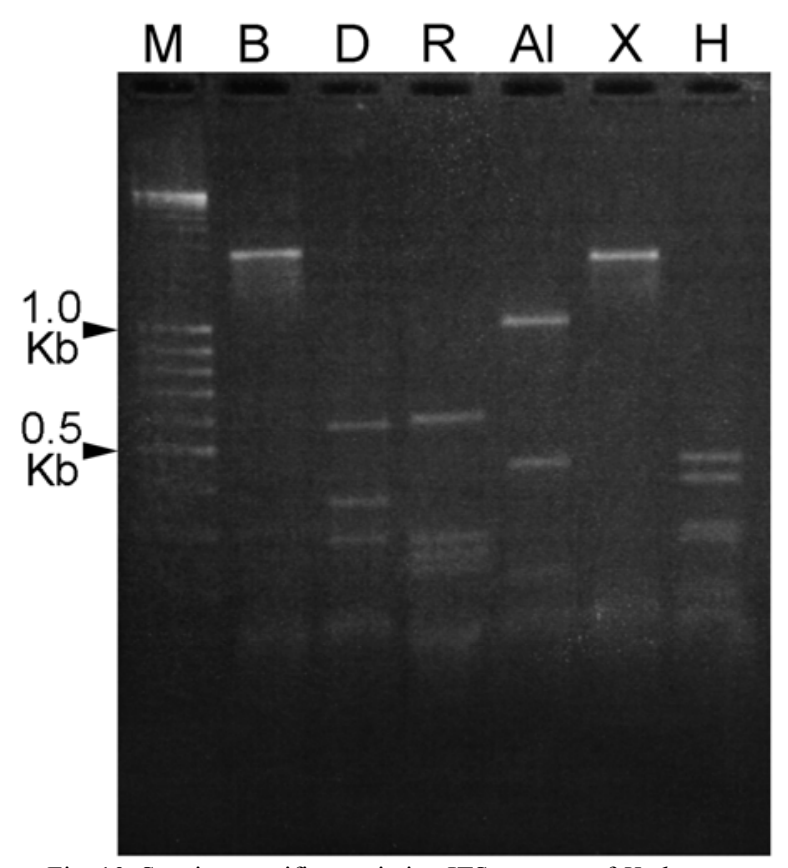

Fig. 10. Species-specific restriction ITS patterns of Xiphinema vuttenezi acquired with the following enzymes: B, BamHI, D, DdeI,

R, RsaI, Al, AluI, H, HinfI, X, XbaI ; M, Molecular marker.

\section{Acknowledgements}

This study was partly funded by projects WETLANET (FP7 Capacities), CEBDER (National Science Fund), project ANIDIV, funded by the Bulgarian Academy of Sciences and POSDRU/107/1.5/S/76888 Project.

\section{References}

Altschul S. F., Madden T. L., Schaffer A. A., Zhang J., Zhang Z., Miller W., LipMAN D. J. (1997): Gapped 
BLAST and PSI-BLAST: a new generation of protein database search programs. Nucleic Acids Res., 25: 3389 3402

Avgelis A. D., TzORTZAKAKIS E. A. (2001): Occurence of viruses and Xiphinema spp. in vineyards of the Greek islands of Paros and Limnos. Phytopathol. Mediterr., 40: $284-288$

BARSI, L. LAMBERTI, F. (2000a): Morphometric variations and juvenile stages of Xiphinema diversicaudatum (Micoletzky, 1927) Thorne, 1939 and $X$. index Thorne et Allen, 1950 (Nematoda: Dorylaimida) from the former territory of Yugoslavia. Nematol. Mediterr., 28: 171 - 187

BARSI, L. LAMBERTI, F. (2000b): Morphometric variations and juvenile stages of Xiphinema vuittenezi (Nematoda: Dorylaimida) in Serbia. Nematol. Mediterr., 28: 3 - 12

BROWN, D. J. F., TOPHAM, P. (1985): Morphometric variability between populations of Xiphinema diversicaudatum (Nematoda: Dorylaimoidea). Revue Nématol., 1: 15-26 Castillo, P., Vovlas, N., Subbotin, S., Troccoli, A. (2003): A new root-knot nematode, Meloidogyne baetica n. sp. (Nematoda: Heteroderidae) parasitizing wild olive in Southern Spain. Phytopathology, 93: 1093 - 1102

CoHN, E. (1977): Xiphinema italiae. C.I.H Descriptions of Plant parasitic Nematodes, Set 7, No 95

Coiro, M. I., Lamberti, F., Agostinelli, A., Vindimian, M. E. (1989): I Longidoridae nei vigneti del Trentino. II: Il genere Xiphinema Cobb. Nematol. Mediterr., 17: 139- 148 Coomans, A., Huys, R., Heyns, J., LuC, M. (2001): Character analysis, phylogeny and biogeography of the genus Xiphinema Cobb, 1913 (Nematoda: Longidoridae). Annales Sciences Zoologiques, Muse'e Royal de l'Afrique Centrale, Tervuren, 287: 1 - 239

De LuCA, F., Reyes, A., Grunder, J., KunZ, P., Agostinelli, A., De Giorgi, C., LAmberti, F. (2004): Characterization and sequence variation in the rDNA region of six nematode species of the genus Longidorus (Nematoda). J. Nematol., 36: 147-152

FinetTi-Sialer, M. M., CiAncio, A. (2005): Isolate-specific detection of Grapevine fanleaf virusfrom Xiphinema index through DNA-based molecular probes. Phytopathology, 95(3): 262 - 268. DOI: 10.1094/PHYTO-95-0262

Goodey, J. B., Peacock, F. C., Pitcher, R. S. (1960): A redescription of Xiphinema diversicaudatum (Micoletzky, 1927) Thorne, 1939 and observations on its larval stages. Nematologica, 5: 127 - 135

Gutiérrez-Gutiérrez, C., Rius, J. E. P., CantalaPiedra-Navarrete, C., Landa, B. B., Castillo, P. (2011): Prevalence, polyphasic identification, and molecular phylogeny of dagger and needle nematodes infesting vineyards in southern Spain. Eur. J. Plant Pathol., 129(3): 427 - 453. DOI: 10.1007/s10658-010-9705-y

He, Y., Subbotin S., Rubtsova, T. V., Lamberti, F., Brown, D. J. F., MoEns, M. (2005): A molecular phylogenetic approach to Longidoridae (Nematoda: Dorylaimida). Nematology, 7: 111 - 124

Heyns, J. CoOmnas, A. (1984): The genus Xiphinema in South Africa. VIII. Xiphinema diversicaudatum (Micoletzky, 1927) Thorne, 1939. Phytophylactica, 16: $117-120$
IVezic, M., Raspudic, E., LAmberti, F., Pribetic, D. J. (2002): Xiphinema spp. in vineyards of Istra Peninsula in Croatia. Helminthologia, 39 (2): 119 - 120

JAWHAR, J., VovLAS N., Digiaro, M. (2006): Occurrence of Xiphinema index in Lebanese vineyards. J. Plant Pathol., 88(1): 117 - 119

Jeanmougin, F., Thompson J. D., Gouy, M., Higgins, D. G., GIBSON, T. J. (1998): Multiple sequence alignment with Clustal X. Trends Biochem. Sci., 23: 403 - 405

KUMARI, S. (2004): The occurrence of Xiphinema vuittenezi, X. pachtaicum and Longidorus leptocephalus (Nematoda: Dorylaimida) in the Central Czech Republic. Helminthologia, 41: $103-108$

KuMARI, S. (2006): Xiphinema simile (Nematoda: Longidoridae) in the Czech Republic and a note on other Xiphinema species. Helminthologia, 43: 43 - 50. DOI: 10.2478/s11687-006-0009-X

Kumari, S., Decraemer, W., LiŠKovÁ, M. (2009): Molecular and morphological delineation of Longidorus poessneckensis Altherr, 1974 (Nematoda: Dorylaimida). Eur. J. Plant Pathol., 123: 125 - 137. DOI: 10.1007/s10658-008-9348-4

Kumari, S., Di CeSARE, A. (2013): Nicotinamide dehydrogenase subunit 4 analysis of Xiphinema diversicaudatum and Xiphinema simile (Nematoda: Longidoridae). Eur. J. Plant Pathol., 136 (4): 803 - 810. DOI: 10.1007/s10658013-0208-5

KUMARI, S., LIŠKOVÁ, M. (2009): Molecular confirmation of Xiphinema italiae Meyl, 1953 (Nematoda: Longidoridae) from the Slovak Republic. Helminthologia, 46(2): 131 - 134. DOI: $10.2478 / \mathrm{s} 11687-009-0025-8$

Lamberti, F., Choleva, B. Agostinelli, A. (1983): Longidoridae from Bulgaria (Nematoda, Dorylaimida) with description of three new species of Longidorus and two new species of Xiphinema. Nematol. Mediterr., 11: $49-72$ Lamberti, F., Iovev, T., Choleva B., Brown, D. J. F., Agostinelli, A., RAdicci, V. (1997): Morphometric variation and juvenile stages of some longidorid nematodes from Bulgaria with comments on the number of juvenile stages of Longidorus africanus, L. closelongatus and Xiphinema santos. Nematol. Mediterr., 25: 213 - 237

Lamberti, F., Sabová, M., De Luca, F., Molinari, S., Agostinelli, A., CoIro, M., VAlockÁ B. (1999): Phenotypic variation and genetic characterization of Xiphinema populations from Slovakia (Nematoda: Dorylaimida). Nematol. Mediterr., 27: $261-275$

Lazarova, S., Elshishka, M., Groza, M., Peneva, V. (2010): Nematodes of Longidoridae and Trichodoridae from riparian habitats in Bulgaria. (Abstract). Proceedings of $30^{\text {th }}$ International Symposium of European Society of Nematologists, 19 - 23 September, 2010, Vienna, Austria, p. 127

LišKovÁ, M., BRown, D. J. F. (1998): Longidoridae (Nematoda) associated with walnut tree (Juglans regia L.) in Slovak Republic. Helminthologia, 35(2): 95 - 99

LiŠKOVÁ, M., BROWN, D. J. F. (1999): The occirrence of Longidoridae (Nematoda) in forests in the Slovak Republic. Helminthologia, 36(1): $49-56$ 
LIŠKOVÁ, M. STURHAN, D. (2000): Occurrence and ecology of Longidoridae (Nematoda: Dorylaimida) in floodplain forests in the Slovak Republic. Helminthologia, 37(2): 113 $-117$

LIŠKOVÁ, M. (1995): Nematodes - virus vectors in the rhizosphere of fruit-trees and soft fruits in Slovakia. Helminthologia, 32(1-2): $43-48$

LIŠKOVÁ, M. (1997): Nematodes of the family Longidoridae in the rhizosphere of the grapevines in the Slovak Republic. Helminthologia, 34: 87 - 95

LIŠKOVÁ, M. (2001): Longidoridae (Nematoda: Dorylaimida) in natural grassland of fluvial plains and river banks in the Slovak Republic. Helminthologia, 38: 47 - 50 Luc, M., Lima, M. B., Weischer, B., FlegG, J. J. M. (1964): Xiphinema vuittenezi n. sp. (Nematoda: Dorylaimidae). Nematologica, 10: 151 - 163

Magunacelaya, J. C., Lamberti, F., Ahumada, M. T. (2004): On the occurence of Xiphinema index Thorne et Allen in Chile. Nematol. Mediterr., 32(2): 235 - 236

MacFarlane, S. A., Neilson, R., Brown, D. J. F. (2002). Nematodes. Adv. Bot. Res., 36: $169-198$.

Meza, P., Aballay, E., Hinrichsen, P. (2012): Morphological and molecular characterisation of Xiphinema index Thorne and Allen, 1950 (Nematoda: Longidoridae) isolates from Chile. Nematropica, 42: $41-47$

Peneva, V., Choleva, B. (1992): Nematodes of the family Longidoridae from forest nurseries in Bulgaria. II. Genus Xiphinema Cobb, 1913. Хелминтология, 32: 47 - 66

Pitcher, R.,S., SidDiQI, M. R., Brown, D. J. F. (1974): Xiphinema diversicaudatum. C.I.H Descriptions of Plant parasitic Nematodes, Set 4, No. 60.

RocA, F., Bravo, M. (1997): Multivarite analysis of Xiphinema diversicaudatum and some related species (Nematoda: Longidoridae). Fundam. Appl. Nematol., 20: $357-369$

RocA, F., LAmBerTI, F. (1993): I Longidoridae (Nematoda, Dorylaimida) delle regioni Italiane. XIII. La Toscana. Nematol. Mediterr., 21: $261-272$

RocA, F., LAmberti, F., Agostinelli, A. (1988): I Longidoridae (Nematoda, Dorylaimida) delle regioni Italiane. VII. Il Piemonte e la valle D"Aosta. Nematol. Mediterr., 16: $35-51$

RocA, F., Lamberti, F., Agostinelli, A. (1989): I Longidoridae (Nematoda, Dorylaimida) delle regioni Italiane. IX. La Sicilia. Nematol. Mediterr., 17: 151 - 165

RocA, F., LAmberti F., D’ERrico, F. P. (1991): I Longidoridae (Nematoda, Dorylaimida) delle regioni Italiane. XI. La Campania. Nematol. Mediterr., 19: 139 - 154

RomAşcU, E., ZINCA, V. (1974): Xiphinema index Thorne et Allen 1950 (Nematoda: Dorylaimidae) a new nematode pest of vine. Analele I.C.P.P., 10: 273 - 283

RomAŞCU, E., ZINCA, V. (1977): Xiphinema vuittenezi (Ne- matoda: Dorylaimidae) - a parasitic nematode of the vine roots. Analele I.C.P.P., 12: $283-288$

RoMAȘCU, E. (1971): Xiphinema americanum Cobb , 1913 and Xiphinema italiae Meyl, 1953 (Nematoda: Dorylaimidae), new pests of vine. Analele I.C.P.P., 7: 203 - 209

RoMAșCU, E. (1981): Xiphinema diversicaudatum (Micoletzky, 1927) Thorne, 1939 (Nematoda, Dorylaimoidea) a pest vector of plant virus disease. Analele I.C.P.P., 16: $261-265$

SEINHORST J.W. (1959): A rapid method for the transfer of nematodes from fixative to anhydrous glycerin. Nematologica, 4: $67-69$

SIDDIQI, M. R. (1974): Xiphinema index. C.I.H Descriptions of Plant parasitic Nematodes, Set 3, No. 45

STURHAN, D. (1963): Beitreg zur Systematik der Gattung Xiphinema Cobb, 1913. Nematologica, 9: 205 - 214

Sturhan, D., Wouts, W. M., Grandison, G. S., BARBER, C. J. (1997): Nematode vectors of plant viruses in New Zealand. N.Z. J. Zool., 24: $309-322$

Tamura, K., Peterson, D., Peterson, N., Stecher, G., NEI M., KuMAR, S. (2011): MEGA5: Molecular evolutionary genetics analysis using Maximum Likelihood, Evolutionary Distance, and Maximum Parsimony methods. Mol. Biol. Evol., 28: 2731 - 2739. DOI:10.1093/molbev/msr121 TAYLOR, C. E., BROWN, D. J. F. (1997): Nematode vectors of plant viruses. CAB International. Retrieved from http:// www.amazon.com/Nematode-Vectors-Plant-Viruses-Taylor /dp/0851991599286 pp.

THORNE, G. (1939): A monograph of the nematodes of the superfamily Dorylaimoidea. Capita Zoologica, 8: 1 - 261 TIEFEnBrunner, A., TIEFEnBRUnNER, W. (2004): Longidoridae (Nematoda: Dorylaimida) from the rhizosphere of the wild growing grape (Vitis vinifera ssp.silvestris) in the riparian woods of the rivers Danube and March in Austria. Helminthologia, 41: 45 - 53

Tzortzakakis, E. A., Pateras, D., Charoulis, A. (2006): Occurrence of Xiphinema species in grapevine areas of Tyrnavos with comments on the distribution of $X$. italiae in Greece. Helminthologia, 43(3): 186 - 187. DOI: 10.2478/s11687-006-0034-9

Vrain, T. C., WaKarchuK, D. A., Levesque, A., HAMILTONR, I. (1992): Intraspecific DNA restriction fragment length polymorphism in the Xiphinema americanum group. Fundam. Appl. Nematol., 15: 563 - 573

WALKER, G. E. (2004): New Australian record for Xiphinema vuittenezi on Vitis vinifera. Australas. Plant Pathol., 33: 131 - 132. DOI: 10.1071/AP03071

Wang, X., Bosselut, N., Castagnone, C., Voisin, R., ABAD, P., Esmenjaud, D. (2003): Multiplex polymerase chain reaction identification of single individuals of the Longodorid nematodes Xiphinema index, X. diversicaudatum, $X$. vuittenezi and $X$. italiae using specific primers from ribosomal genes. Nematology, 93 (2): $160-166$ 